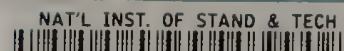

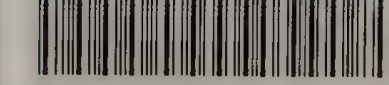

$A \unlhd l l 0 b$

\section{Reference}

NBS

Publications

NBSIR 84-2826

\title{
Demand Limiting Algorithms for Energy Management and Control Systems
}

U.S. DEPARTMENT OF COMMERCE

National Bureau of Standards

Center for Building Technology

Building Equipment Division

Washington, DC 20234

February 1984

Sponsored by:

Office of Building and Community Systems

U.S. Department of Energy

U.S. Navy Civil Engineering Laboratory

U.S. Department of Defense 


\section{DEMAND LIMITING ALGORITHMS FOR} ENERGY MANAGEMENT AND CONTROL SYSTEMS

Cheol Park

U.S. DEPARTMENT OF COMMERCE

National Bureau of Standards

Center for Building Technology

Building Equipment Division

Washington, DC 20234

February 1984

Sponsored by:

Office of Building and Community Systems

U.S. Department of Energy

U.S. Navy Civil Engineering Laboratory

U.S. Department of Defense

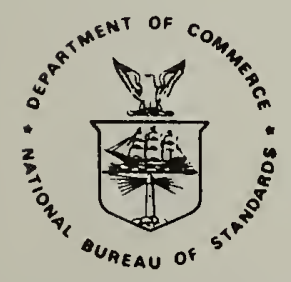

U.S. DEPARTMENT OF COMMERCE, Malcolm Baldrige, Secretary NATIONAL BUREAU OF STANDARDS, Ernest Ambler, Director 


\section{ABSTRACT}

Demand limiting control is one of popular control strategies for electrical energy management in Energy Management and Control Systems (EMCS) in commercial/office buildings. The purpose of demand limiting is to maintain the peak demand level below a predetermined limit by shedding nonessential loads in a building during the peak demand period. In this present report, description of fixed interval metering and sliding window metering for electrical demands are included. Demand limiting calculation procedures discussed are the ideal rate, the predictive, and the instantaneous rate methods. Demand limiting algorithms, which were developed based on available information, are presented. Computer program listings of demand limiting control algorithms in Fortran 77 and an open-loop computer simulation result are included in the appendices.

Key words: electrical demand; electrical energy management; electric power; energy management and control systems; fixed interval metering; ideal rate method; instantaneous rate method; load control; predictive method; sliding window metering. 
LIST OF FIGURES $\ldots \ldots \ldots \ldots \ldots \ldots \ldots \ldots \ldots \ldots \ldots \ldots \ldots \ldots \ldots \ldots$

1. INTRODUCTION $\ldots \ldots \ldots \ldots \ldots \ldots \ldots \ldots \ldots \ldots \ldots \ldots \ldots \ldots \ldots \ldots \ldots$

2. ELECTRICAL DEMANd METERInGS ..................... 4

2.1 DEMAND METERS ............................ 4

2.2 FIXED INTERVAL METERING $\ldots \ldots \ldots \ldots \ldots \ldots \ldots \ldots \ldots \ldots \ldots$

2.3 SLIDING WINDOW METERING $\ldots \ldots \ldots \ldots \ldots \ldots \ldots \ldots \ldots \ldots \ldots$

3. DEMANd limiting Calculation METHOds $\ldots \ldots \ldots \ldots \ldots \ldots \ldots \ldots \ldots$

3.1 IDEAL RATE METHOD ......................... 15

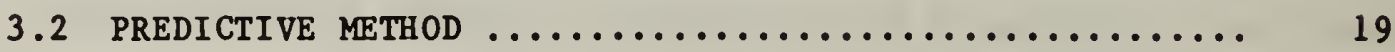

3.3 InSTANTANEOU R RATE METHOD..................... 20

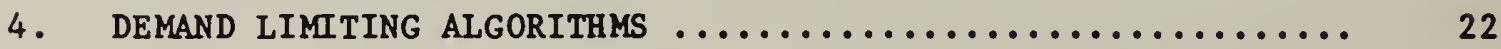

4.1 IDEAL RATE METHOD WITH FIXED INTERVAL ............ 23

4.2 PREDICTIVE METHOD WITH FIXED INTERVAL .............. 24

4.3 PREDICTIVE METHOD WITH SLIDING WINDOW ............. 26

4.4 Instantaneou S Rate method ................... 31

4.5 PREDICTIVE METHOD WITH FLEXIBILITY IN METERING ....... 31

5. LOAD CONTROL ALGORITHM ...................... 35

6. CONCLUSION $\ldots \ldots \ldots \ldots \ldots \ldots \ldots \ldots \ldots \ldots \ldots \ldots \ldots \ldots \ldots \ldots \ldots$

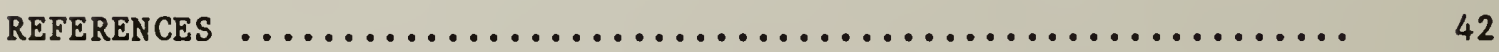

APPENDIX A. Computer Program Listing of the Ideal Rate Method with Fixed Interval-DLRF $\ldots \ldots \ldots \ldots \ldots \ldots \ldots \ldots \ldots \ldots$ A-1

APPENDIX B. Computer Program Listing of the Predictive Method with Fixed Interval - DLPF ................... B-1 
APPENDIX C. Computer Program Listing of the Predictive Method with sliding Window - DLPS .................. c-1

APPENDIX D. Computer Program Listing of the Instantaneous

Rate Method - DLIS .................... D-1

APPENDIX E. Computer Program Listing of the Predictive Method with Flexibility in Metering - DLPFS .......... E-1

APPENDIX F. Computer Program Listing of the Load Control Algorithm - LDONOF ..................... F -1

APPENDIX G. Open-loop Computer Simulation ............... G-1 
Figure 1. A sketch of a small demand meter $\ldots \ldots \ldots \ldots \ldots \ldots \ldots$

Figure 2. Demand metering set-up for high power users $\ldots \ldots \ldots \ldots 7$

Figure 3. Fixed interval metering $\ldots \ldots \ldots \ldots \ldots \ldots \ldots \ldots \ldots \ldots$

Figure 4. sliding window metering $\ldots \ldots \ldots \ldots \ldots \ldots \ldots \ldots \ldots \ldots \ldots$

Figure $5 . \quad$ Ideal rate method with off set $\ldots \ldots \ldots \ldots \ldots \ldots \ldots \ldots \ldots$

Figure 6. Upper and lower limits for the ideal rate method ...... 18

Figure 7. Logic flow diagram of the subroutine DLRF for the

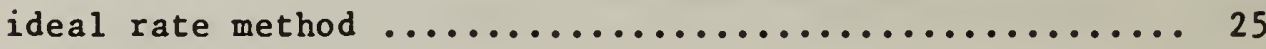

Figure 8. Logic flow diagram of the subroutine DLPFA for the predictive method with fixed interval metering ......... 27

Figure 9. An illustration of sliding window billing method ...... 29 Figure 10. Logic flow diagram of the subroutine DLPSA for the predictive method with sliding window metering $\ldots \ldots \ldots 32$

Figure 11. Logic flow diagram of the subroutine DLP for linking ... 34

Figure 12. Logic flow diagram of the subroutine LDONOF for load

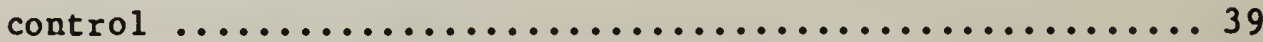


Electrical energy management has an important role in energy management and control systems (EMCS) in buildings. The purpose of electrical energy management is to lower the charges imposed by electric utilities. Although popular strategies for electrical energy management include demand limiting, duty cycling, time-of-day control, scheduled start/stop control, and optimum start/stop control, only demand limiting is discussed in this report.

Electric utility charges are typically based on some combination of electric energy consumption, fuel adjustment, electric demand, ratchet adjustment, and power factor $[1,2]$. Electric energy consumption is defined as the electric energy usage read by a watt-hour meter in $\mathrm{kWh}$, while the fuel adjustment charge is based on the kind and cost of fuel used by the utility. The electric demand charge is the portion of the service charge which is based upon a customer's demand, and will be explained later. A ratchet adjustment is made on the basis of energy use or demand. Finally, the power factor is the relationship between the phase of the current and the phase of the voltage in alternating current distribution systems. (A low power factor can overload generating and distribution networks.) Currently, residential customers are not charged for electric demand and power factor, while industrial and commercial customers may be billed for all or some charges discussed.

Electric demand is defined as the load integrated over a specified time interval [3]. In other words, electric demand is the energy consumption over a specific time interval of 15,30 , or 60 minutes. The time interval is determined by a utility and is called demand interval. The maximum demand is the maximum value of demand measures during a billing period in $\mathrm{kW}$. Charges 
based on maximum demand allow a utility to recover its capital investment in generating and distributing equipment used to meet the maximum demand for electrical power. When the maximum demand of many customers occurs simultaneously, the peak load of the power system will be high, therefore the utility's capital investment will be large. During the off-peak period, a part of the equipment capacity is idle. Because demand charges are high (as much as 30 percent of some customers' bills [4]) and because a demand charge is usually based upon the highest demand that has occurred during a billing period, controlling demand is very important. A high peak demand for just a few minutes can raise the demand charge for the entire billing period.

An electrical demand limiting strategy is outlined by Shih [5]. The purpose of demand limiting is to maintain the peak demand level below a predetermined limit by shedding (disconnecting) nonessential loads in a building during the peak demand period. In conjunction with demand meter pulse signals, Shih presented two demand limiting methods. These are the predictive method (forecasting method), and the ideal rate method. The ideal rate method was used with analog demand limiting meters many decades ago. The concept of demand control was also explored with comprehensive analyses by Militello [6]. On-peak or off-peak metering, automatic load control, and demand billing control are extensively discussed in his paper in addition to the concepts of demand and demand control. The instantaneous rate principle is mentioned as a load shedding technique by Pannkoke [7]. In this technique, the rate of electric energy use is measured at short time intervals and compared with a limiting value. Good examples of the demand computation can be found in Pannkoke's article. Currently, there exist, as discussed above, three calculation methods; i.e., ideal rate, predictive (forecasting) and 
instantaneous methods. These methods are related to the metering technique employed.

Two metering techniques, associated with impulse signals from the demand meter, are known. They are the fixed interval metering and the sliding window metering. The most widely used one is the fixed interval metering in which shedding of loads is generally performed sequentially or rotationally. The loads that have been shed are restored when the demand is lower than a predetermined level. Novak [8] considered on and off times of loads during shedding and restoring activities, keeping the number of on and of $f$ actions to a minimum. A new concept for load shedding, called "comfort fairness," was briefly introduced in an article by Spethmann [9]. The comfort fairness concept is not currently involved in the demand limiting algorithm of this report. The use of this concept can be found in the report of time-of-day control and duty cycling algorithms by May [17].

Although many publications relating to demand limiting are available in the public domain, no detailed information that is suitable for implementation utilizing computers has been found. Software on the market, for practical purposes, is proprietary so that general public has limited access to detailed information. The present report is intended to describe the concept of demand limiting, and the possible implementation of the algorithms to digital control hardware. Metering techniques, calculation principles, and load control algorithms are discussed, and computer programs written in Fortran 77 are. provided. With presumed data, the open-loop computer simulations were carried out, and the results are appended for illustration purposes. It should be noted that demand limit control is a closed loop control in practice. 
Electrical energy consumption and maximum demand are measured by meters and serve as the basis of billing for industrial and commercial customers. A utility and a customer make a contract for the electric charge. Discussion of the contents of such contracts is beyond the scope of this report. Some ideas about the rate structure for these charges may be obtained from papers by Teed [10] and Carpenter [11]. In this chapter, demand meters, fixed interval metering, and sliding window metering will be described.

\subsection{DEMAND METERS}

Ordinarily a utility must provide electric power to any customer in any quantity required. Since alternating-current (AC) power cannot be stored practically, the utility must increase its generating and distributing capacities to meet an increased maximum load condition. This results in larger generators, larger transformers, heavier switches, heavier wires, and so on. Consequently, fixed investment must be increased to meet increased customers' requirements. Such a situation was being investigated as far back as 1892 , and as a result, a dual rate of metering was developed [12]. In this scheme, energy use measured by a watt-hour meter and electric power demand measured by a demand meter determine the charge for billing period.

The demand meter is a device to register the integrated energy used for a specific time interval, namely electric power. There are two different sizes of meters available. One is a small demand meter which is housed in the same 
case of a watt-hour meter. An internal timer with fixed time interval resets the demand reading at the end of each demand measurement interval. The maximum value of the demand reading is indicated by a sweephand maximum demand pointer during the demand period. The pointer can go upward but not downward until reset is made manually when the meter is read. Thus the maximum demand during a billing period is determined. Internal mechanical connections are made between the demand meter and the watt-hour meter. Figure 1 show a sketch of a small meter.

Another type of meter is a large demand meter which is a type of recording instrument separate from the integrating watt-hour meter. Recording can be done on a chart or a magnetic tape. Chart recording demand meters have become obsolete and they are being replaced by newer magnetic tape recording device. For large commercial and industrial users who require more than $500 \mathrm{~kW}$ peak load, large demand meters are installed [13]. The demand meters are linked to the watt-hour meters electrically. Pulses generated by a signal pickup device in the watt-hour meter are fed into the demand meter in which the pulses are totalized for a short time period, and the totalized value is recorded at each sampling instance for recording. A description of the totalization technique can be found in a report by Hurley, Kelly, and Kopetka [14]. More detailed information on demand meters is described elsewhere [12].

For demand control, sampled data from the pulse counter (totalizer) are required for digital processing by a microprocessor or a computer. The sampling rate, $T_{s}$, may depend upon the system of interest. By installing an optical or mechanical device, electric pulses can be generated in small demand meters like those discussed earlier. Figure 2 shows a possible arrangement 


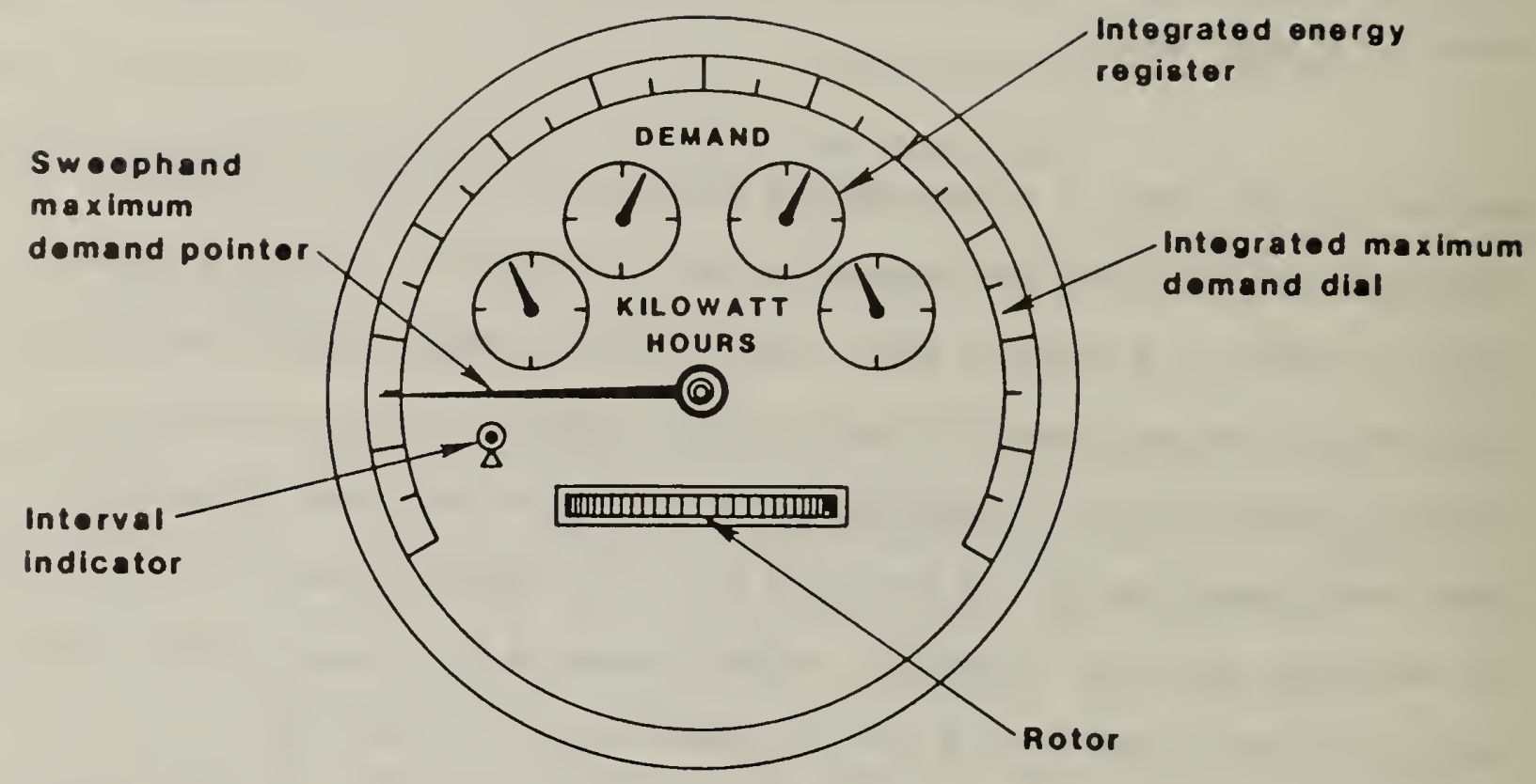

Figure 1. A sketch of a small demand meter 


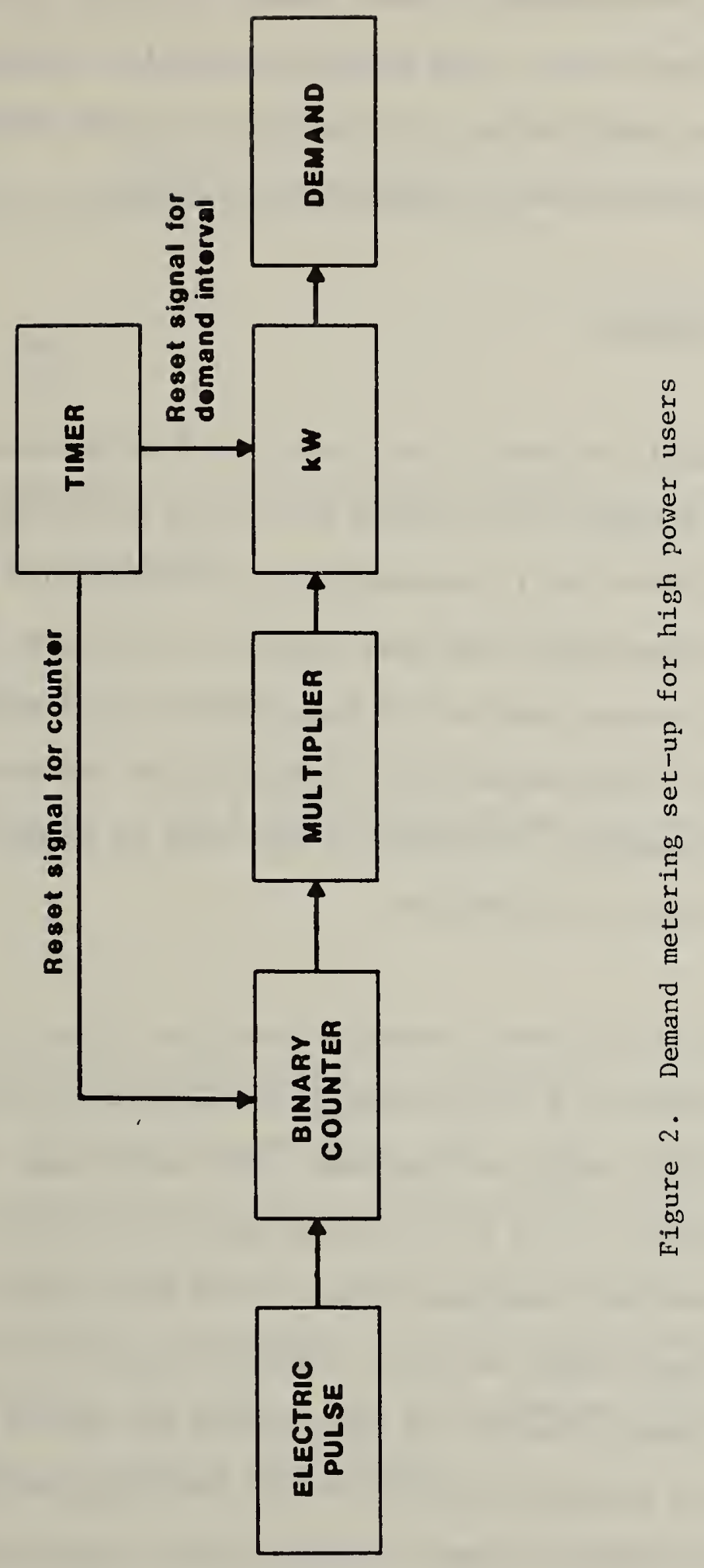


for demand metering for a customer using large amounts of electric power. This illustration provides a general view of demand metering. Besides the pulses from the watt-hour meter, it is sometimes possible to obtain (from the utility) a second pulse signal which indicates the end of one demand period and the start of the next period; a demand interval signal.

\subsection{FIXED INTERVAL METERING}

Fixed interval metering is the most widely used method in the measurement of electric demand. For a fixed time interval (15, 30, or 60 minutes set by the utility), the average power use is computed to be the demand for that period. At the end of each billing period, the peak demand is then taken by the power company, and billing is made based on the peak demand in conjunction with the rate schedule. Since billing methods differ depending on the contract between the utility and its customers, no attempt is made here to discuss a customer's payment to a utility in terms of dollars.

A requirement of the fixed interval metering technique is that a reset signal must be available at the end of every demand interval so that the demand meter can again accumulate the energy use from zero. The reset signal can be originated from an internal clock of the demand meter, or from an external clock. The reset signal may also come directly from the utility to the demand meters. Should the reset signal fail once, measured demand will be doubled if the required electric power remains the same for two consecutive demand periods. Thus, special attention must be paid to detecting the reset signal when fixed interval metering is used to control demand, especially if the reset signal is not continuously synchronized with the power company. 
When the demand interval is $D$, and the sampling period is $T_{s}$, the number of samples in the demand interval, $n$, will be $D / T_{s}$. If the total number of pulses during the $i-t h$ sampling period is given by $N_{i}$, the average power, $\bar{p}$, which is the demand during the whole demand interval, is expressed by:

$$
\overline{\mathrm{P}}=\frac{1}{\mathrm{n}} \sum_{i=1}^{\mathrm{n}} \frac{\mathrm{CN}_{\mathrm{i}}}{\mathrm{T}_{\mathrm{s}}}
$$

where $C$ is the conversion factor in $\mathrm{kWh}$ per pulse. Since $\mathrm{C}$ and $\mathrm{T}_{\mathrm{s}}$ are usually constant, equation (1) yields:

$$
\bar{P}=\frac{C}{T_{8} n} \sum_{i=1}^{n} N_{i}
$$

The instantaneous power at the $i-t h$ sampling instant may be given by:

$$
P_{i}=\frac{\mathrm{CN}_{i}}{T_{s}}
$$

It should be noted that, since the unit of $C$ is $k$ Wh per pulse, both $D$ and $T_{s}$ must be in hours. The term "instantaneous power" means the average power during a sample period when the pulse counting technique with a watt-hour meter is used for power measurement. However, if continuous direct power measurement is available, for example, by means of using analog devices (voltmeter and ammeter), the sampled data at an instant can be considered the instantaneous value of power at that instant.

As an example, if $D$ is $30 \mathrm{~min}, T_{s}$ is $60 \mathrm{sec}, N_{i}$ is 10 pulses for $i-t h$ period, and $C$ is $0.72 \mathrm{kWh}$ per pulse, the instantaneous power at the $i-t h$ period can be 
computed from equation (3), resulting in:

$$
P_{i}=\frac{(.72)(10)}{\frac{60}{3600}}=432 \mathrm{~kW}
$$

If the measured number of pulses for all sampling intervals is the same, the average power in the demand interval is from equation (2):

$$
\bar{P}=\frac{0.72}{\left(\frac{60}{3600}\right)(30)} \sum_{i=1}^{30}(10)=(1.44)(300)=432 \mathrm{~kW}
$$

This result coincides with the previous result as expected.

Furthermore, suppose pulse counts of 100 and 200 pulses during the first and second sampling periods, respectively, were obtained during the demand period, then the integrated demand becomes

$$
\bar{P}=(1.44)(100+200)=432 \mathrm{~kW} .
$$

We arrive at the same answer as before. This indicates that high peak power for a short time period does not really increase the demand because the demard is an integrated quantity over the demand interval. Figure 3 illustrates fixed interval metering.

\subsection{SLIDING WINDOW METERING}

A reset signal, preferably synchronized with the utility's metering system, is a requirement for using the fixed interval method. When reset signal is not available or is missing due to equipment failure, fixed interval metering is 


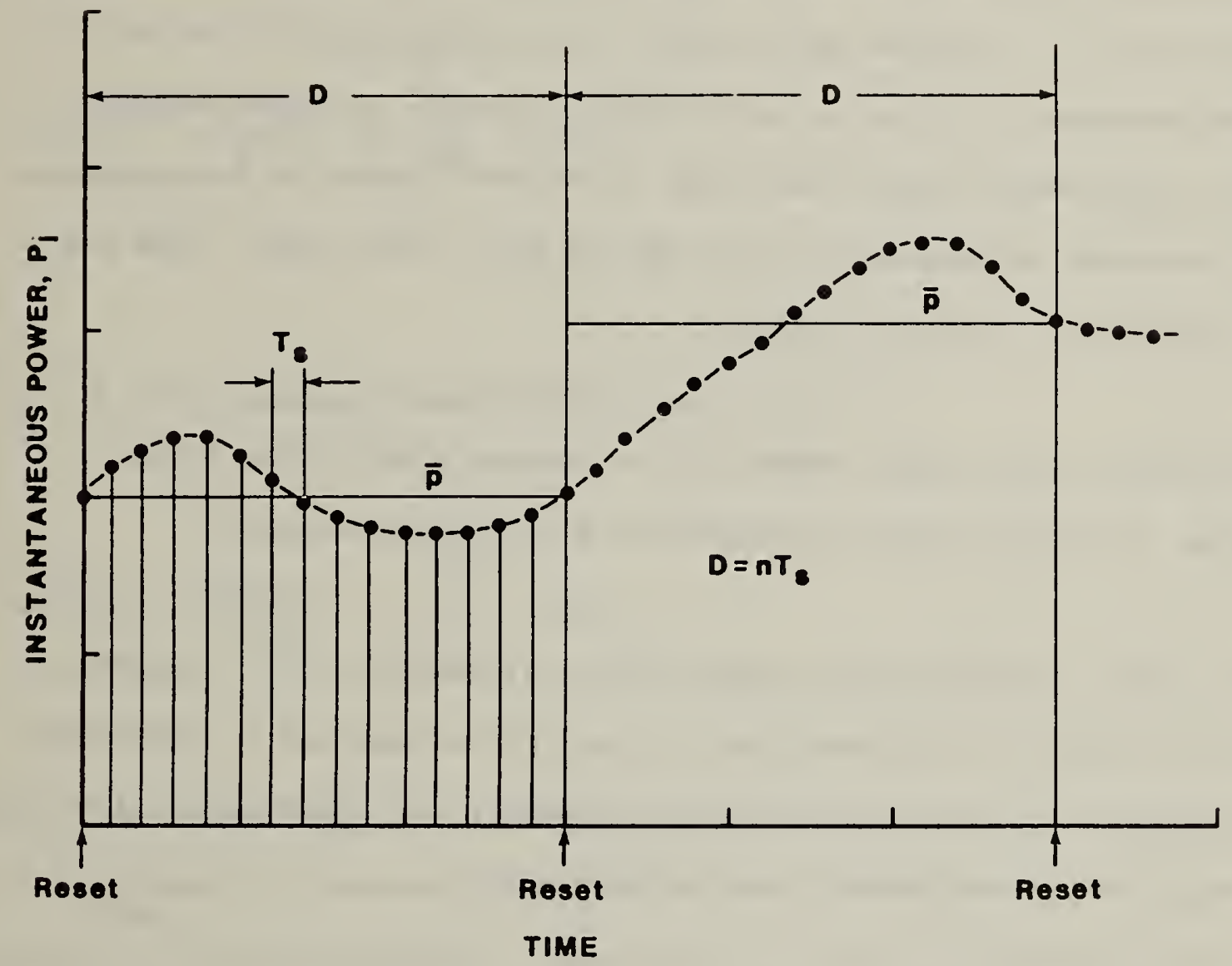

Figure 3. Fixed interval metering 
not desirable. Sliding window metering is the method that is usually used when there is no synchronized reset pulse. In this technique, the demand interval is still fixed. If the current sampling instant is moved to the next sampling period and it becomes the upper limit of the integration, then the lower limit moves ahead by one sampling period. In this way, the total number of observations remains unchanged as time progresses so the demand during a demand period is calculated at the end of each sampling period and one of those measurements will be the peak demand. Unlike the fixed interval method, this method requires knowledge of the past history of instantaneous power measurements between the lower and the upper time limits. This means that dynamic data storage is needed.

Because dynamic data memory capability is required with sliding window metering, a computer must be incorporated with the demand meter.

If the energy consumption rate (power), $P(t)$, is sampled with a sampling period, $T_{S}$, and if a zero-order hold filter [15] is employed to reconstruct the sampled data, the integrated energy consumed, $E(t)$, starting at time $t_{8}$ and ending the current time, $t$, can be given by:

$$
E(t)=\int_{t_{s}}^{t} P(t) d t \approx \sum_{k=0}^{n-1} P\left(k T_{s}\right) T_{s}
$$

where $\mathrm{n}$ is the total number of sampled data in the demand period, $D$. The demand in that period, $P(t)$, is computed by dividing $E(t)$ by $D$, namely 


$$
\bar{P}(t)=\frac{E(t)}{D}=\frac{1}{n} \sum_{k=0}^{n-1} P\left(k T_{s}\right)
$$

At the next time step, $t+T_{s}$, retaining the same index $k$ for time $t$, the demand yields:

$$
\bar{P}\left(t+T_{s}\right)=\frac{E\left(t+T_{8}\right)}{D}=\frac{1}{n} \sum_{k=1}^{n} P\left(k T_{8}\right)
$$

At $t+2 T_{8}$, the computed demand becomes (see figure 4):

$$
\bar{P}\left(t+2 T_{s}\right)=\frac{E\left(t+2 T_{8}\right)}{D}=\frac{1}{n} \sum_{k=2}^{n+2} P\left(k T_{s}\right)
$$

Clearly, one can see that the sliding window method is a moving integration method. Instead of a zero-order hold filter, use of the linear point connector [15] can be considered to minimize errors when the sampling rate is low.

The integration method employed in this report is the simple trapezoidal method. It would not be surprising if the customer's computation of total energy usage during a billing period disagrees with the utility's meter reading because different integration methods may be used. It is obvious that the accuracy of integration will be increased as the sampling rate increases. 


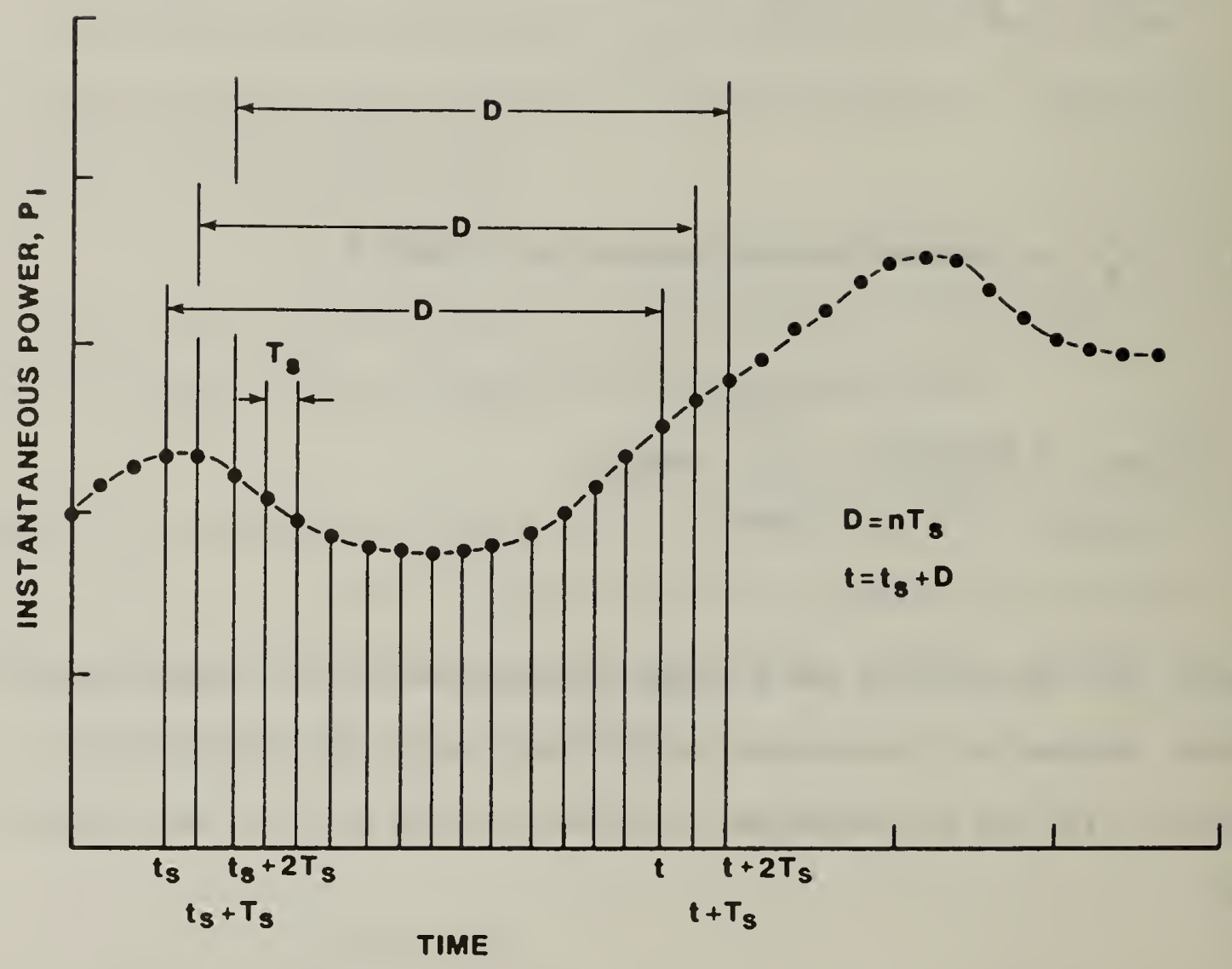

Figure 4. Sliding window metering 
The highest demand during a billing period is of ten used as a basis for determining the demand charge for a future billing period. The main purpose of demand limiting is therefore to avoid establishing new higher peaks by maintaining the maximum demand within a preset 1 imit. Non-essential or lower priority loads are usually turned off when load shedding becomes necessary by a demand limiting decision-making process. The load shedding decision is made by a calculation method that is selected as the most appropriate method for a given situation. There exist three well-known calculation methods at the present time $[2,5,7,8,9,16]$. They are the ideal rate, the predictive (or forecasting), and the instantaneous rate methods.

\subsection{IDEAL RATE METHOD}

The ideal rate method was first used with analog type demand controllers. In this method, the quantity of energy consumed is measured and accumulated by the demand controller. The integrated value is then compared with a maximum allowable value which varies with respect to time in a predetermined rate. The principle of the ideal rate uses linear prediction to determine the allowable energy at the next sampling instant, and incorporates fixed interval metering. This principle may also be applied on large metering devices that may include computers.

Figure 5 illustrates the ideal rate method. As seen on the figure, an adjustable off set, $E_{0}$, is provided to delay required shedding action to a later stage of time in the demand interval instead of having it in the earlier 


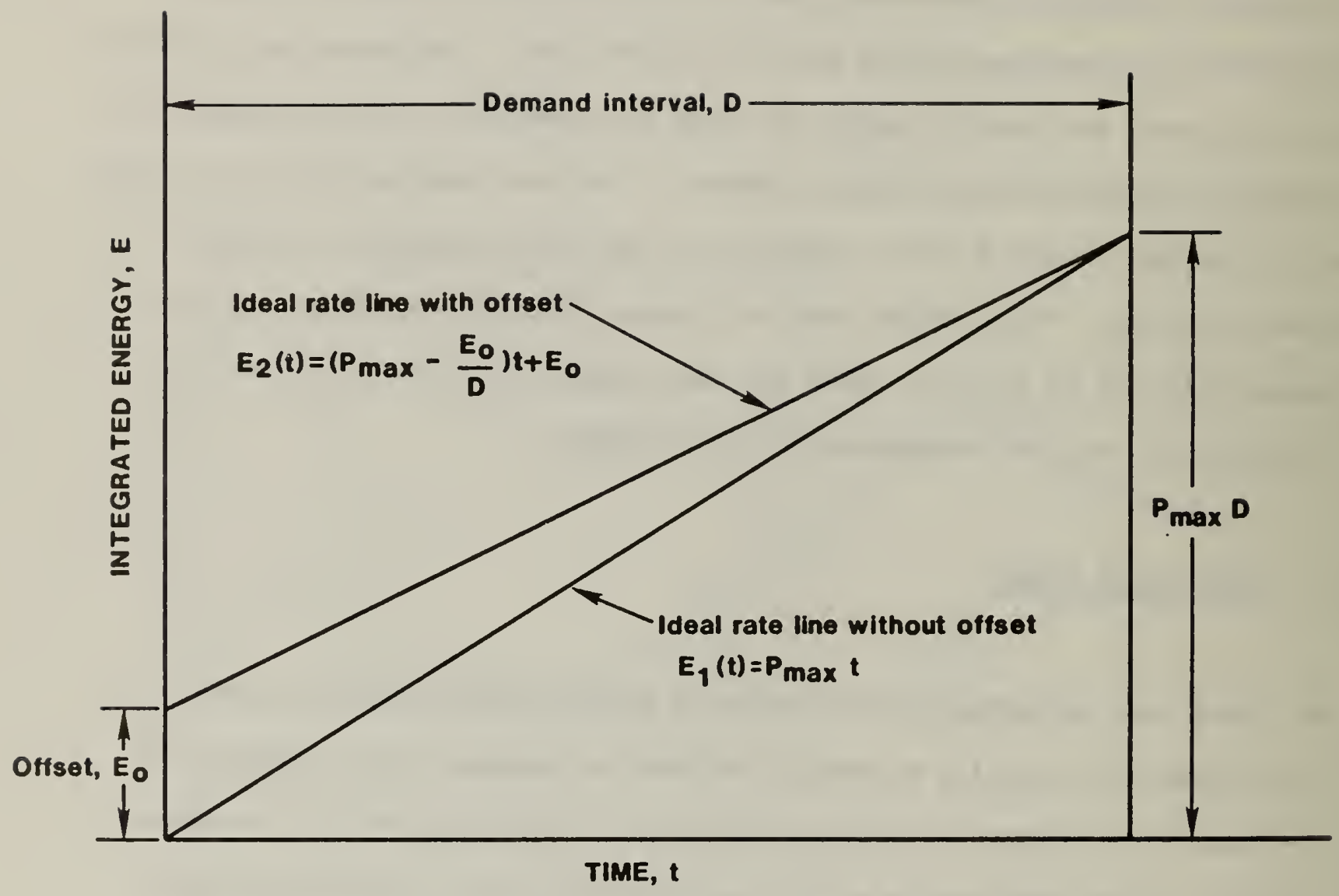

Figure 5. Ideal rate method with offset 
time. This offset permits restoring of the shed loads during the previous demand period. If all loads which have been shed are restored at the beginning of the next demand interval, the offset value should be set at a relatively high value.

If the maximum allowable demand power during a demand interval is selected as $\mathrm{P}_{\max }$, the integrated energy in that interval will be $\mathrm{D}$ times $\mathrm{P}_{\max }$. The ideal rate line without the offset, $E_{1}(t)$, as seen in figure 5 , has the slope of $P_{\max }$ When the offset value is other than zero, the integrated energy

expression with respect to time, $E_{2}(t)$, can be given by:

$$
E_{2}(t)=\left(P_{\max }-\frac{E_{0}}{D}\right) t+E_{0}
$$

where $E_{0}$ is the offset.

Since $E_{0}$ and $D$ are positive constants, the rate of change of $E_{1}(t)$ is always greater than that of $E_{2}(t)$. The ideal rate of change is thus $\left(P_{\max }-E_{0} / D\right)$ instead of $P_{\max }$. Remember that the ideal rate method is used only with fixed interval metering.

$E_{2}(t)$ may be used as an upper limit for the demand limit control, (see figure $6)$.

$$
E_{\max }(t)=E_{2}(t)
$$

Whenever the measured, integrated energy usage, $E(t)$, exceeds the limit value, $\mathrm{E}_{\max }(t)$, load shedding takes place. It is also desirable to restore the loads which were shed if the rate of energy use is much lower than the ideal rate. 


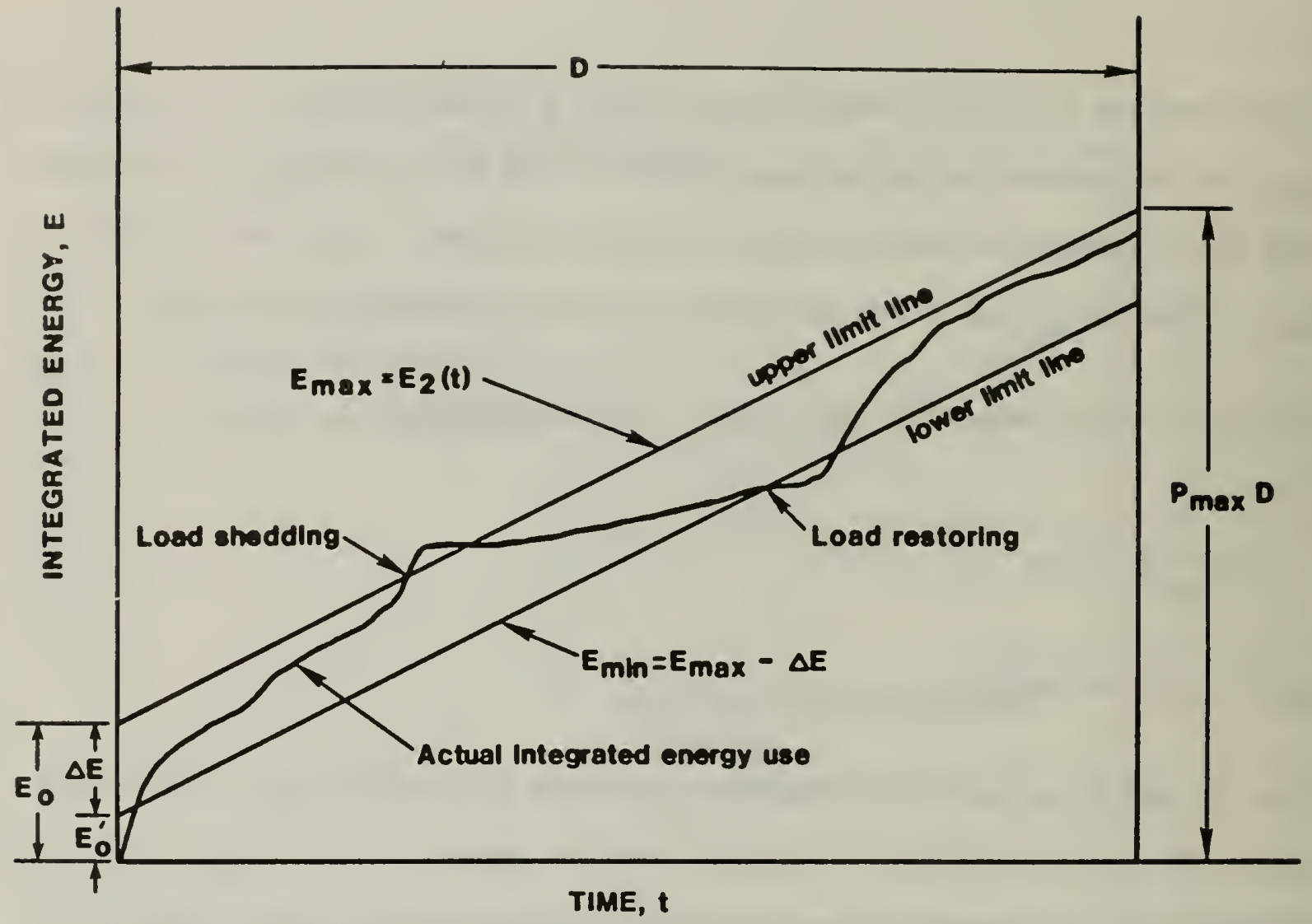

Figure 6. Upper and lower Iimits for the ideal rate method 
A minimum limit value can be assigned so that load restoring may be performed if the energy usage is less than the limit value that is expressed by:

$$
E_{\text {min }}(t)=\left(P_{\max }-\frac{E_{0}}{D}\right) t+E^{\prime} 。
$$

where $\mathrm{E}_{0}^{\prime}$ is the intersection that is less than $\mathrm{E}_{0}$ in the amount of $\Delta \mathrm{E}$. In terms of the differential, $\Delta E$, equations (9) and (10) give a relationship as:

$$
E_{\min }(t)=E_{\max }(t)-\Delta E
$$

Depending upon the value of $E$ at a particular time, the load control actions may be selected. No control action is needed if the $E(t)$ stays in the range as

$$
E_{\min }(t) \leq E(t) \leq E_{\max }(t)
$$

\subsection{PREDICTIVE METHOD}

At each measurement instant in a demand interval, the instantaneous rate of energy consumption is measured and a forecast of the energy consumption at the end of the demand interval is made. This calculation procedure is called the predictive or forecasting method. Either fixed interval or sliding window metering may be used with the predictive method. The predictive principle needs more computational effort than the ideal rate principle. As a result, unlike the ideal rate principle, the predictive method can be employed only with a computer. For simplicity, the predictive method with fixed interval metering will be described in this section. 
Assume the desired peak demand is $P_{\max }$. When the peak demand occurs, the accumulated energy use will be $P_{\max } D$, in which the demand interval is a constant. Knowing that $E(t)$ is the integrated energy consumption from the beginning of the demand interval to a specific time, $t$, the total energy consumption at the end of the demand interval can be predicted. A simple linear prediction may be made based on the energy use at the current time and at the previous sampling period. The predicted energy consumption without correction (shedding loads) at the end of the demand interval, $E_{p}(t)$, is given by:

$$
E_{p}(t)=\left(\frac{D-t}{T_{8}}\right)\left[E(t)-E\left(t-T_{s}\right)\right]+E(t)
$$

The value of $E_{p}(t)$ is compared with $E_{\max }\left(=P_{\max } D\right)$ at a certain time. Loads are then shed when $E_{p}$ exceeds the preset value $E_{\max }$ Loads may be restored when $E_{p}$ is less than a limit given by

$$
E_{\text {min }}=P_{\text {min }} D^{D}
$$

where $P_{\min }$ is the preset value of power selected as the lower limit.

\subsection{INSTANTANEOUS RATE METHOD}

With the instantaneous rate method, the rate of energy consumption is measured at short time intervals and each measurement is compared with a predetermined limiting value. Whenever this instantaneous rate exceeds the upper limit, $P_{\text {max }}$, load shedding takes place. When the instantaneous rate of energy use is 
below the limit that is preestablished as the lower limiting value, $P_{m i n}$, loads are restored. The control band, which is the difference between the upper and the lower limits, is needed to minimize rapid cycling of the load control action. As long as the measured power at time $t, P(t)$, stays in the range as given by $P_{\min } \leq P(t) \leq P_{\max }$, loads are neither shed nor restored. The advantage of using this instantaneous rate principle is that synchronization with the utility's demand interval is not necessary. This principle, however, does not involve the demand interval. 


\section{DEMAND LIMITING ALGORITHMS}

In previous sections, the general principles of demand limiting have been reviewed. In this section, the algorithms developed for use with computers will be discussed. The ideal rate and the predictive methods incorporate fixed interval metering. The predictive method may also use sliding window metering, while the instantaneous method does not need specific metering. The load control algorithm is not given with the main algorithms, but is presented in Section 5 .

The demand limit algorithms use the trapezoidal integration method in which the average value of the power measured at the current sampling instant and the power measured at the past sampling instant is computed. The average power value is then multiplied by the sampling period to give the instantaneous value of energy consumption at the current time. This approach provides less computational error than the approach using a zero-order holder. Although the accuracy of integration can be improved with a high sampling rate, the system under consideration usually limits the sampling rate.

The algorithms presented here need supporting hardware and software to perform the actual load shedding. With the aid of the supporting software and hardware, the pulse countings can be entered and resulting control action signal can be transmitted to the device of interest. Computer programs are written in FORTRAN 77 and given in the appendices. 


\subsection{IDEAL RATE METHOD WITH FIXED INTERVAL}

The computer algorithm of the ideal rate method is quite simple. Because of using fixed interval metering with this method, a demand interval reset signal must be provided. The important input data is the instantaneous power, $P(t)$, determined by measuring the number of pulses from a watt-hour meter for a sampling period. An expression of the instantaneous power at a sampling instant is given by equation (3). The calculation procedure of power using equation (3) is not included in the algorithm given in this report, because the power can also be determined from direct measurement 8 of the electric current and the voltage at an instant.

For a given demand period, $D$, and sampling interval, $T_{s}$, the average energy consumption rate is calculated, and then is compared with the preset ideal rate as described in the section 3.1. The ideal rate is a function of the maximum allowable power, $P_{m a x}$, the offset, $E_{o}$, and the demand interval. The actual energy usage, $E(t)$, is compared with the maximum energy use up to the point of time from the beginning of the interval. Load shedding occurs if $E(t)>E_{\max }(t)$ and loads are restored if $E(t)<E_{\min }(t)$, in which $E_{\max }(t)$ and $E_{m i n}(t)$ are the upper and lower limiting quantities at time $t$. The amount of load to be shed or restored is calculated by:

$$
\Delta P=\left(P_{\max }-E_{o} / D\right)-\widetilde{P}(t)
$$

where $\widetilde{P}(t)=\left(P(t)+P\left(t-T_{s}\right)\right) / 2$ 
For simplicity, $\mathrm{P}_{\max }$ is a constant, but if the rate schedule contains

different rates for different times-of-day, $P_{\max }$ needs to be varied according to a predetermined schedule.

A flow chart of the ideal rate method in conjunction with fixed interval metering is depicted in figure 7. No load shedding or restoring is performed if the reset signal at the end of the demand interval is missed. Load control is resumed when the next reset signal is received.

A computer program (DLRF) for this algorithm appears in Appendix A.

\subsection{PREDICTIVE METHOD WITH FIXED INTERVAL}

The predictive method using fixed interval metering has been described in Section 3.2. The algorithm for this metering will be explained briefly here. With this algorithm, the ultimate value of energy consumption at the end of the demand period is forecasted. At every sampling time, the forecasting is made and load shedding is performed if the predicted value exceeds the preset value.

To avoid exceeding the preset limit, the amount of power subject to shedding, $\Delta P$, is determined from equation (13) and the demand limit value of $P_{\max }$.

$$
\Delta p=\frac{E_{\max }-E_{p}(t)}{D-t}=\frac{P_{\max } D-E_{p}(t)}{D-t}
$$

By differentiating equation (17) with respect to time, using the assumption that the predicted energy usage at each time during the remaining time in the 

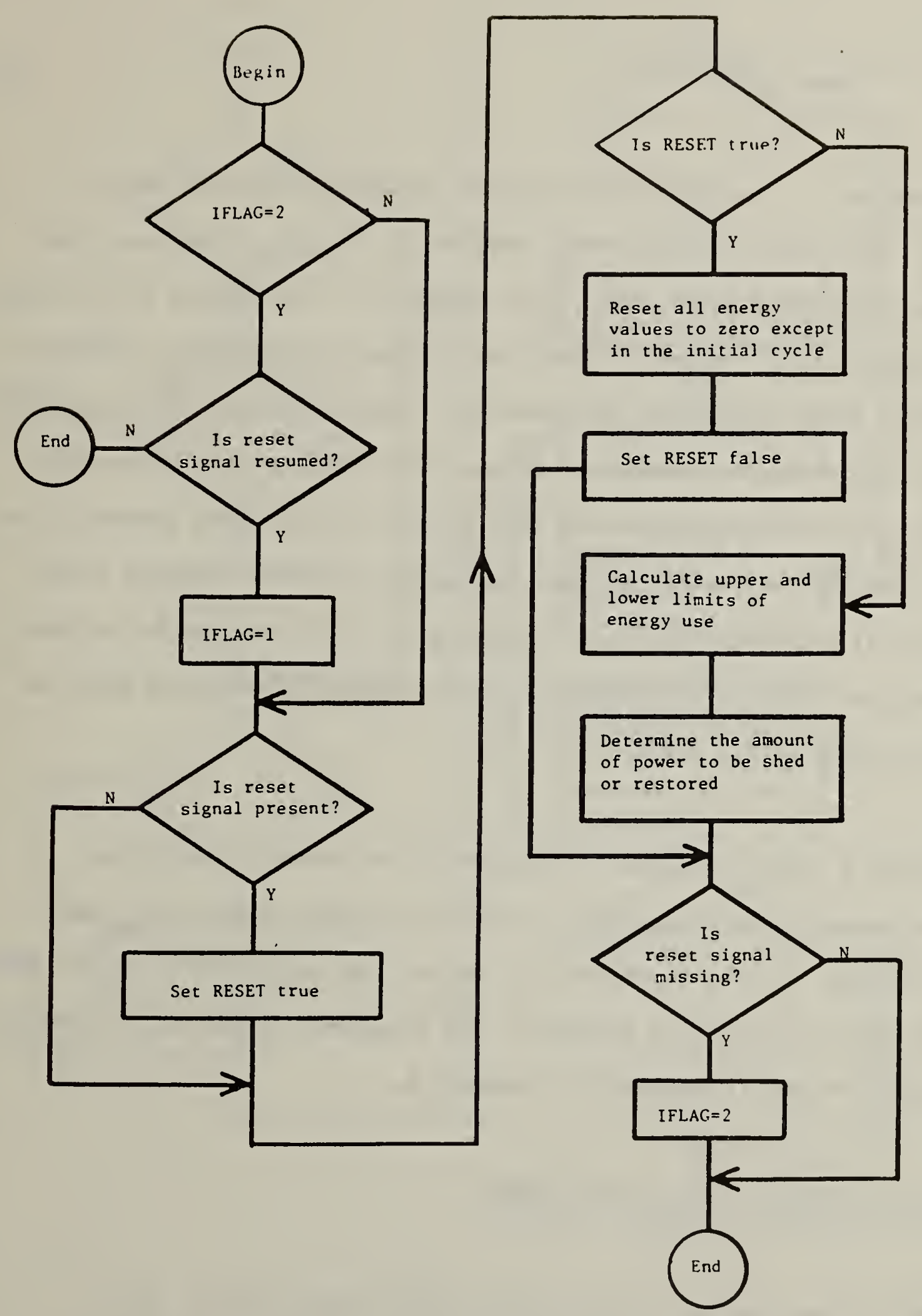

Figure 7. Logic flow diagram of the subroutine DLRF for the ideal rate method 
demand period remains unchanged, i.e. $E_{p}(t)=E_{p}$, the following result is obtained :

$$
\frac{d(\Delta P)}{d t}=-\left(P_{\max } D-E_{p}\right) /(D-t)^{2}
$$

As time approaches $\mathrm{D}$, the denominator becomes smaller, resulting in an increment of the rate of change in $\Delta P$, provided $E_{p}>P_{m a x} D$. This means that for the same forecasted value of $E_{p}$, load shedding is less likely to be needed at the beginning of the demand interval but the need progressively increases as time passes until the end of the interval. Because of this effect, demand limiting control using the predictive method with fixed interval metering allows an electricity customer to use high power at first, then gradually cut down as the end of the demand interval approaches to prevent setting a new peak demand. As a result, utility load curves show a roller-coaster effect with an overload state at the beginning and an underload condition near the end of each demand period [16].

Figure 8 shows a logic flow chart of the predictive method using fixed interval metering. Given $P_{m a x}, P_{m i n}$ and $D$, this method predicts the load shedding required. If the reset pulse is missed, no load control action takes place until the reset pulse is restored. The computer program DLPF is based on this algorithm and is provided in Appendix B.

\subsection{PREDICTIVE METHOD WITH SLIDING WINDOW}

As mentioned in the previous section, the roller-coaster effect can be observed in the utility's load curves when customers employ demand limit 

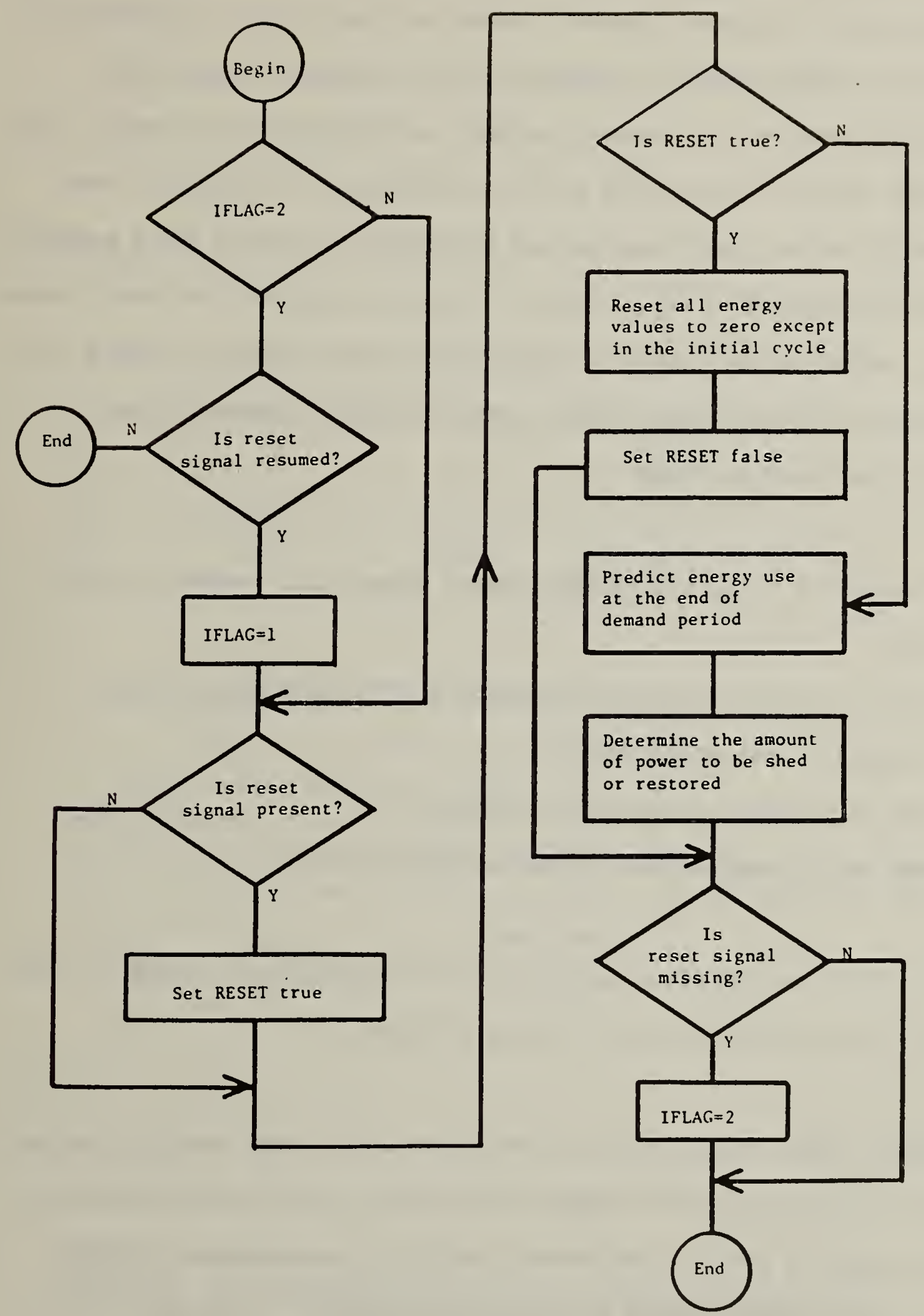

Figure 8. Logic flow diagram of the subroutine DLPFA for the predictive method with fixed interval metering 
controls based on fixed interval metering. Peaks and valleys appear in the load distribution, resulting in short-time overloading and underloading. Although short-time high power places a burden on the utility, the charge for the short-period demand cannot be imposed on the consumers because the integrated energy use for the demand interval is still below the preset value. Various billing methods are devised by some utilities. For instance, one utility company charges its industrial and commercial customers for a maximum demand that is calculated by the addition of any two adjacent 15-minute energy consumptions, while another utility computes the demand charge by adding six adjacent 5-minute energy usages. These cases of sliding window billing methods are illustrated in figure 9.

The predictive method using the sliding window metering is needed for the following cases:

(1) When the reset signal at the end of each demand period is not provided by the utilities.

(2) When the reset pulse misses temporarily.

(3) When the sliding window billing method is used.

For the third case, the sampling period for the instantaneous energy use rate must be less than the period of the sliding billing.

In the algorithm under consideration, the demand at the next sampling instant is predicted on the basis of the demands computed at the current time and at the previous sampling period. The demand period, $D$, the maximum allowable demand, $P_{\max }$, the minimum demand for restoring loads, $P_{m i n}$, and the sampling period, $\mathrm{T}_{\mathbf{8}}$, are required input data. 

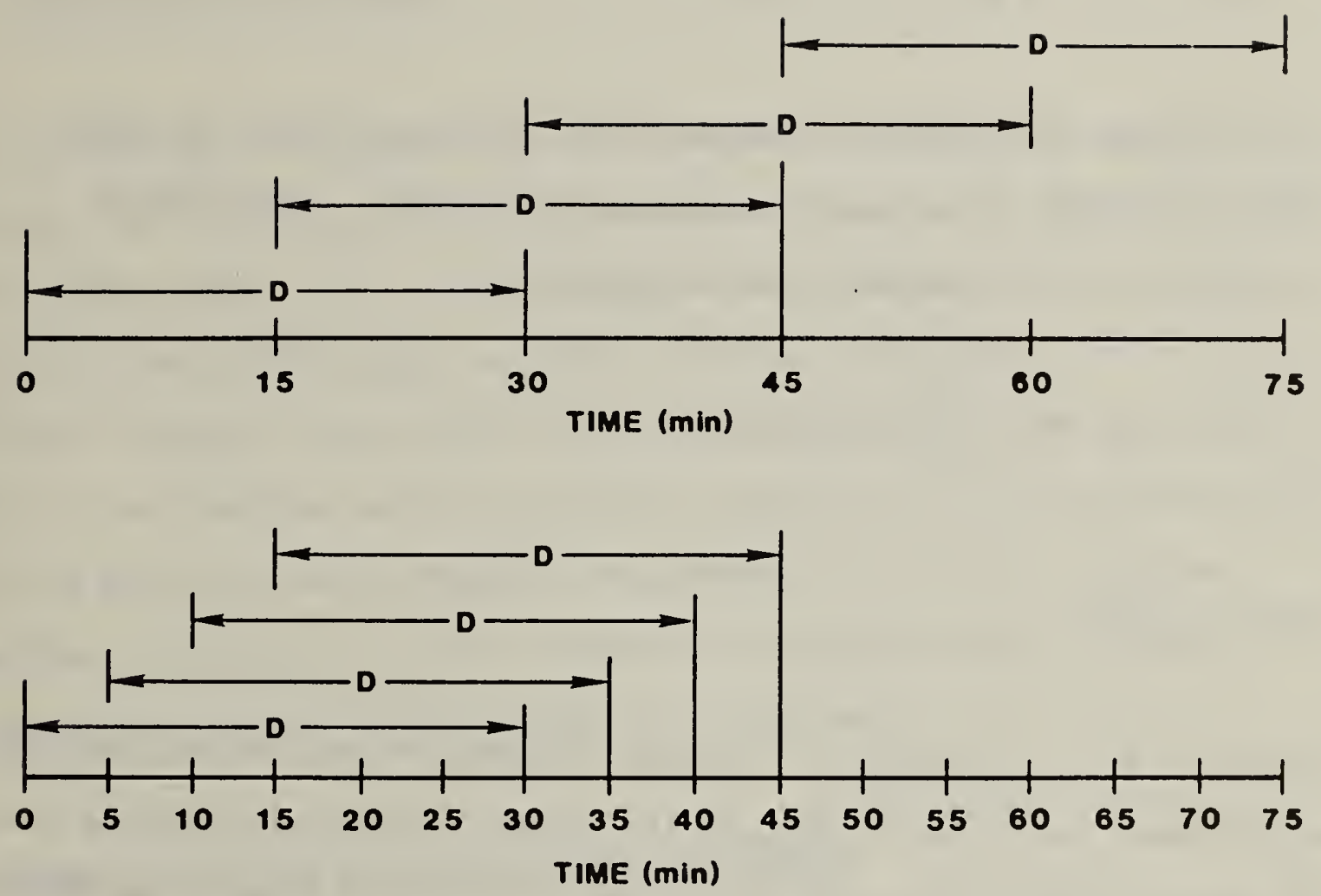

Figure 9. An illustration of sliding window billing method 
With this algorithm, the demand at the next time step is unknown and thus must be forecasted from known values. Since the present and past energy consumptions are known, the energy consumption for a given demand period at time $t+T_{s}$ can be expressed using a linear extrapolation as:

$$
E\left(t+T_{s}\right)=2 E(t)-E\left(t-T_{s}\right)
$$

where $E(t)$ and $E\left(t+T_{s}\right)$ may be obtained from equations (4) and (6) after substituting $\widetilde{P}(t)$ as defined in equation (16) for $P(t)$. The value of $E\left(t-T_{s}\right)$ can be calculated using the equation:

$$
E\left(t-T_{s}\right)=\frac{D}{n} \sum_{k=-1}^{n-2} \widetilde{P}\left(k T_{s}\right)
$$

where $\mathrm{n}=\mathrm{D} / \mathrm{T}_{\mathrm{S}}$.

By letting $E\left(t+T_{s}\right)$ be $E_{p}(t)$, a predicted energy consumption one sampling period ahead, and by letting $E_{\text {max }}$ be the the maximum allowable demand times the demand interval $\left(=\mathrm{P}_{\max } \mathrm{D}\right)$, the amount of electrical power to be shed when $E_{p}(t)$ exceeds $E_{m a x}$ yields:

$$
\Delta P=\frac{E_{\max }-E_{P}(t)}{T_{S}}
$$

When $E_{p}(t)$ is lower than $E_{m i n}$, which is the product of $P_{m i n}$ and $D$, loads can be restored by: 


$$
\Delta P=\frac{E_{\text {min }}-E_{p}(t)}{T_{S}}
$$

Figure 10 shows the logic flow of the predictive method with the sliding window metering. The computer program, DLPS is given in Appendix C.

\subsection{INSTANTANEOUS RATE METHOD}

The instantaneous rate method uses a very simple algorithm. The required input data are $P(t), P_{\max }$ and $P_{\min }$. The instantaneous energy consumption rate is the average value of the measured power at the present and the past. Load shedding occurs if $\widetilde{\mathrm{P}}(t)>\mathrm{P}_{\max }$, and load restoring takes place if $\widetilde{\mathrm{P}}(t)<\mathrm{P}_{\min }$. The demand interval is not needed and the sampling period is not specifically involved. The sampling period is needed in equation (3) if the measurement of pulses is made in order to determine the power at an instant. Since the algorithm is so simple, the logic diagram is not provided here. However, Appendix D provides the computer program listing, DLIS.

\subsection{PREDICTIVE METHOD WITH FLEXIBILITY IN METERING}

The algorithm introduced here is a combined version of the predictive methods with the fixed interval metering which appeared in Section 4.2 and the sliding window metering which was discussed in Section 43 . With this algorithm, one of two metering schemes can be selected depending upon the user's choice. When the fixed interval method is chosen and the demand interval reset signal is missed unexpectedly, the metering method is automatically switched to the sliding window metering. This automatic 


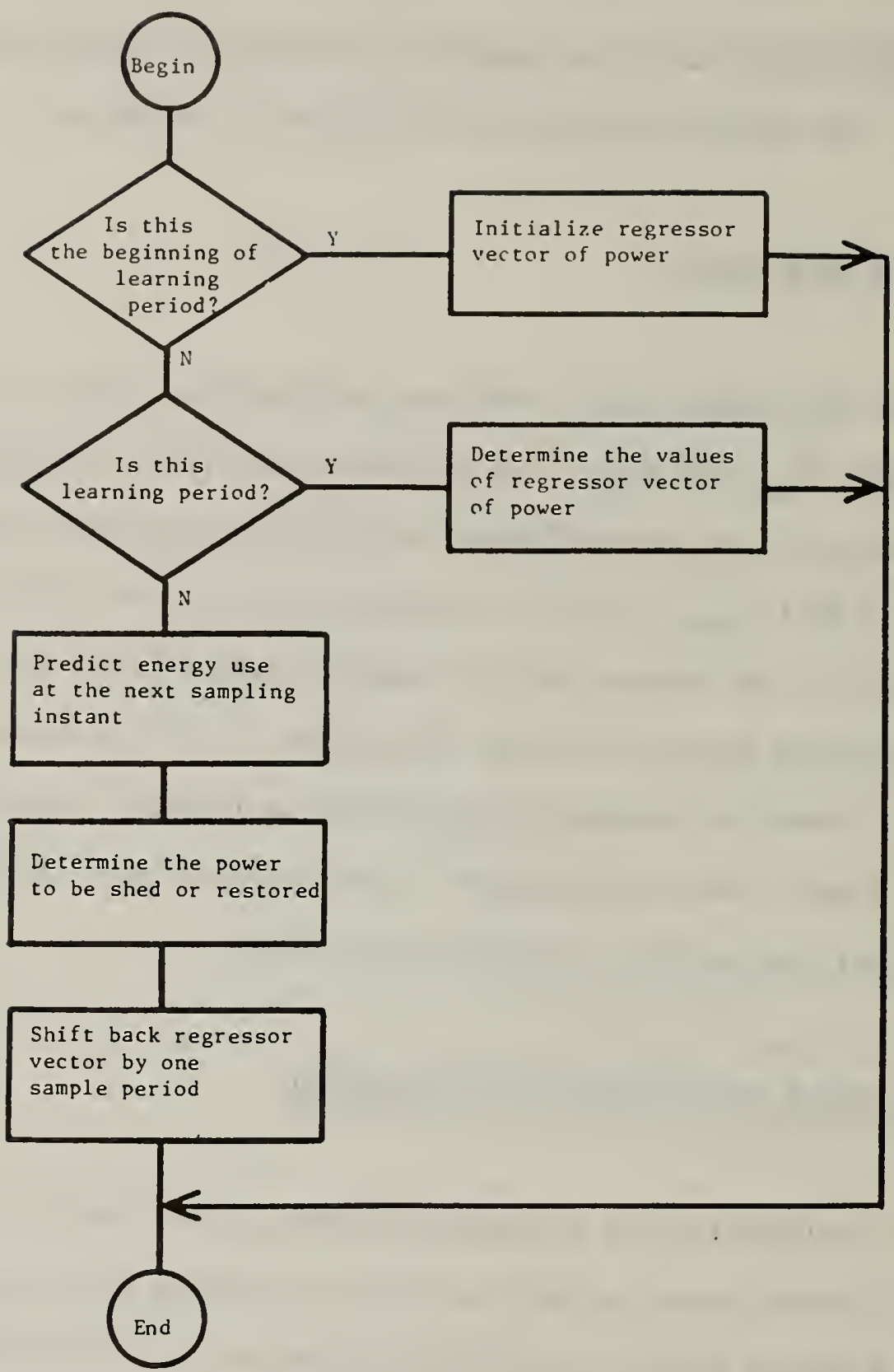

Figure 10. Logic flow diagram of the subroutine DLPSA for the predictive method with sliding window metering 
changeover helps to prevent the accidental creation of a new peak demand when an unexpected thing happens such as a broken communication link between the reset signal source and the computer. Fixed interval metering is restored as as soon as the reset pulse is detected again. Variable peak demand distributions based on the time-of-day rate schedule may also be incorporated.

The computer program for this algorithm is lengthier than others in this report, because it allows for flexibility in metering. The logic flow of the linking program is shown in figure 11. Because the flow charts of predictive methods used in this algorithm are similar to the ones which appeared in figures 8 and 10, they are not presented here. The computer program listing, DLPFS, can be found in Appendix E. 


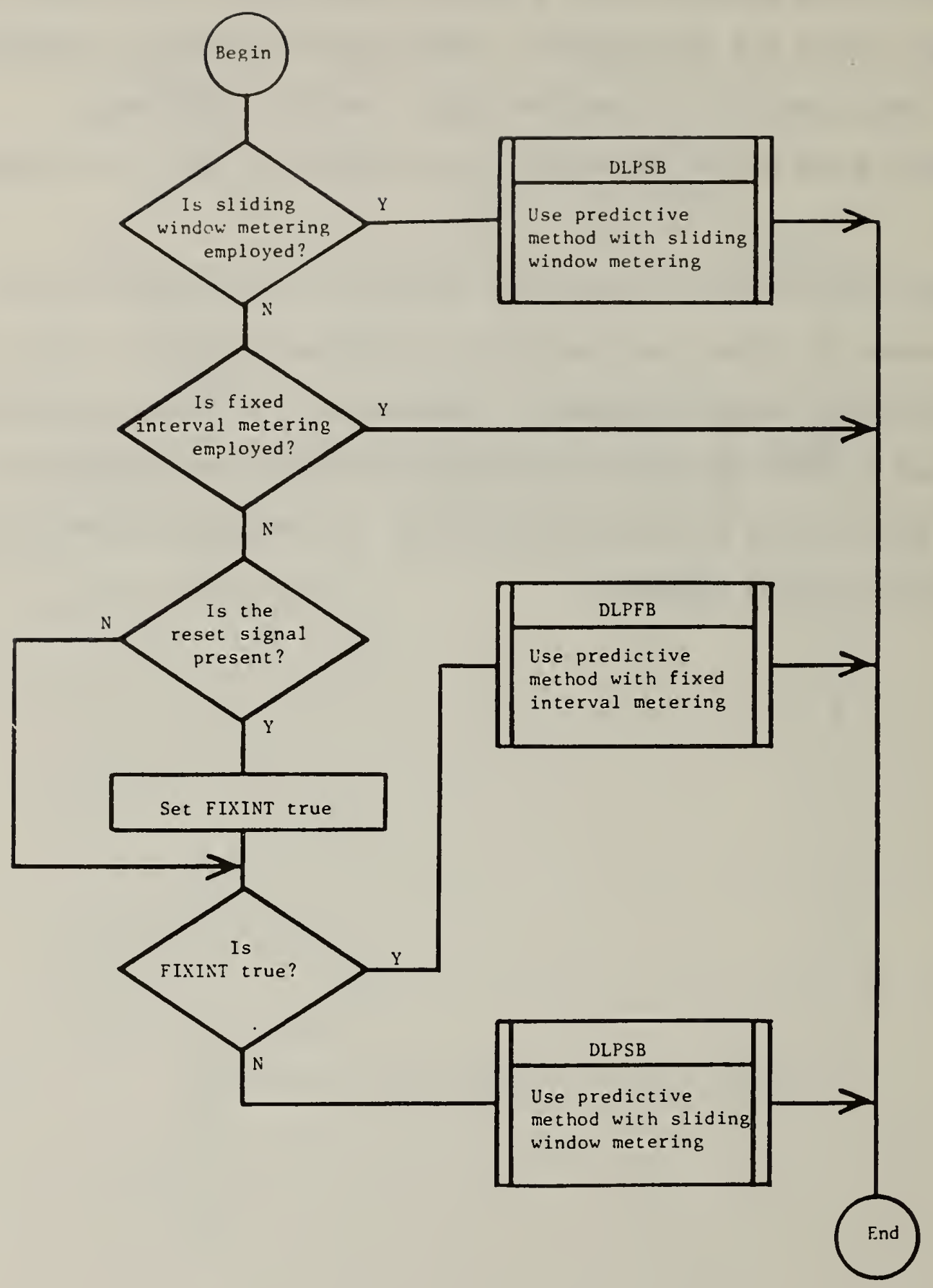

Figure 11. Logic flow diagram of the subroutine DLP for linking 
Controlling loads is part of the job required by demand limiting control. For clarity, the load control algorithm is separately discussed here. Excellent discussions of load control are given in papers by Zilko [2], Spethmann [9], Novak [8], and Shih [5]. Based upon these previous works, the present load control algorithm was developed. This algorithm sheds or restores loads sequentially or rotationally. Provisions for inhibiting short cycling of equipment are made. However, a "comfort fairness" concept [10] is not included but the application of such a concept can be found elsewhere [17].

As pointed out by Pannkoke [7], resistance and motor loads can be shed. Shedable resistance loads include lighting, electric space heaters, boilers, electric furnaces, electric ovens, electric water heaters, battery chargers, de-icers, etc. Motor loads would be fans, pumps, air compressors, refrigeration compressors, etc. Selective loads to be controlled may be anything that can be turned off without harming equipment, significantly impairing comfort, endangering the safety of personnel, or affecting production capability. Elevators, emergency equipment, essential lighting, and computers must be excluded from a list of candidates for shedding. If such loads are included in the list, they must be assigned the highest priority (i.e., not to be shed).

Sequential load shedding is carried out depending upon priority levels of loads. The lowest priority load is shed first and restored last, while the load with the highest priority is cut off last and turned on first. However, 
when a number of loads are classified with the same priority, the order for shedding is determined on a rotational base (round-robin). With the rotational load shedding, a load shed first will be restored first. Each load has a rating and loads are selected and shed until the accumulated loads being shed satisfy the shedding requirement.

It is possible that loads with low priority might experience rapid cycling which might shorten the life of the equipment. To prevent short cycle operations, time parameters are set for minimum off-time and minimum on-times. The minimum off-time ensures that once a load is shed, it will not be turned back on before a predetermined safe period has elapsed. This is particularly needed for the refrigeration system compressors. On the other hand, the minimum on-time is needed so that once a load is turned on, it will remain on for a reasonable time and is essential to prevent motors from being shut off before reaching full rotational speed.

In addition to these two time parameters, Novak [8] described the maximum offtimes of loads. A noticeable change in temperature, humidity, air quality, etc. does not permit a certain type of load to be turned off for more than a specific period. Careful analysis of limiting conditions can determine the length of the maximum off-period of each load. Also, particularly during an initial cycle of load control, delay times for starting loads are necessary to prevent sudden surges of power. Delay times for each load can be set in order to make a smooth start-up during an initial start period of equipment rather than turning on a large number of loads all at once.

The algorithm for controlling loads presented here as the subroutine LDONOF 
incorporates all the elements mentioned above. To use this algorithm, a table must be prepared prior to the start of program. Load identification number, priority, average required power, delay time, minimum off-time, minimum ontime, and maximum off-time are tabulated and stored as one of the input files for the demand limiting program. The priority listed in the table is referred to as global priority. In contrast to the global priority, local priority levels are generated internalig by the algorithm for loads with the same level of global priority.

There are two subroutines, PUSB and POP, that support the main load control routine (LDONOF). One assigns the highest local priority to the load that is most recently shed (PUSB) and the other assigns the lowest local priority to the load most recently restored (POP). Using local priority, the rotational order is created for loads with the same global priority. It is important to point out that even if a load is in the lowest level of priority, it is not shedable if the minimum on-time requirement has not been met. On the other hand, if the minimum off-time for a load has not elapsed, the load cannot be restored. Implementation of these requirements in the algorithm has increased its complexity.

The load controller algorithm is as follows:

(1) Set up local priority levels for each global priority level. Two local priority levels are assigned in a sequential order, one for turn-off and another for turn-on.

(2) Turn on loads during the initial cycle after delay times have passed.

(3) If a power decrease is demanded by a decision-making algorithm as 
given in Chapter 4, and only if minimum on-times have passed, start to shed loads with the lowest priority. Then assign the highest local priority to the load which has just shut off.

(4) Restore loads, if a power increase is allowed, and if minimum offtimes have passed. A load with the highest priority is restored first. Once a load is back on, assign the lowest local priority to the load.

(5) If the maximum off-time of a load has elapsed, restore the load regardless of its priority.

(6) Increase on and off times by one sample period for the use in next time step.

(7) Go to step (3).

The output values of the load control algorithm are logical values (true or false). If the logical value of a load is true, it is expected that the load is turned on, otherwise the load is turned off. A logical value itself cannot be used to directly to control any device. A command given by a high level language must be transformed into signals that are associated with switching devices. Generally machine language subprograms are involved to speed up the process. Therefore, appropriate software and hardware are needed with the load control algorithm.

Figure 12 show 8 the logic flow diagram for the subroutine LDONOF, and its computer program appears in Appendix $F$ with the PUSH and POP subroutines. To aid hardware implementation, computer simulations using the open-loop assumption are described in Appendix G. 

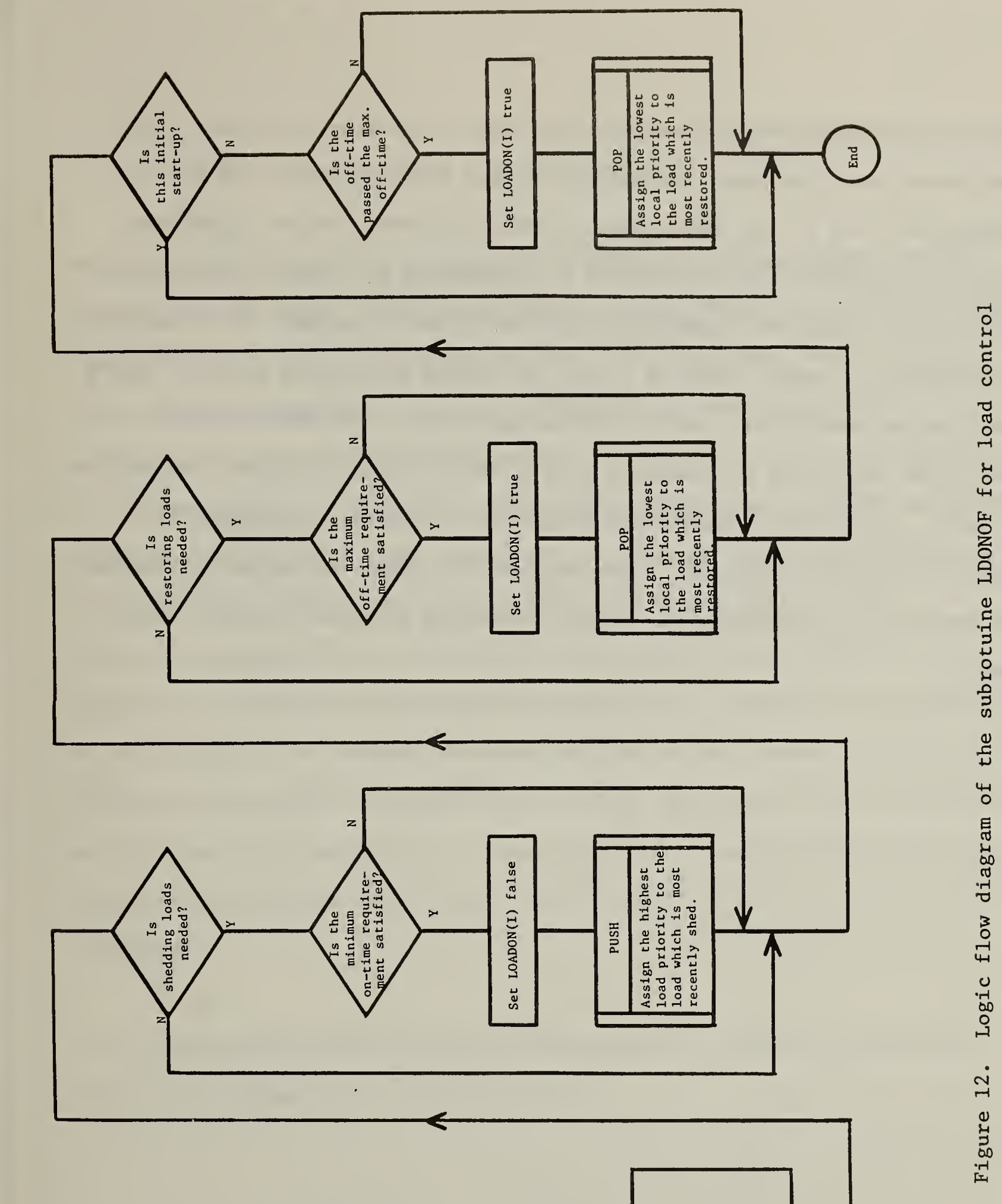
Duty cycle, time-of-day, scheduled start/stop, or optimum start/stop control may be active at the same time that the demand limiting control is in operation. Such a case could cause a conflict between control algorithms. This kind of problem can be resolved by reassigning the level of priority of each control algorithm depending on the conditions to be met. For instance, for shedding, a demand limiting controller should have higher priority than a duty cycling controller. But for restoring activity, the duty cycling controller can ignore a request to turn on by the demand limiting control. As a result, a high level supervisory controller is required to control all control algorithms involved. Since coordination among strategies is discussed by Spethmann [9] and May [17], further discussion will not be made in this report. 


\section{CONCLUSION}

Demand limiting control is an important strategy for energy management and control systems (EMCS). The use of demand limiting control can not only avoid establishment of a new peak demand during a billing period, but it can also reduce energy consumption. Selection of the appropriate demand limit algorithm depends upon the billing method of the utility and the availability of a demand period reset signal. Thus, a demand limiting algorithm should be tailored according to a given situation. In the load control algorithm used with a demand limiting control, the input value determination is the customer's responsibility. The customer must provide sufficient load flexibility to permit adequate shedding capability. Appropriate coordination of the hardware, the computer programs provided in this report, and supporting software are essential for successful controls. When other control strategies are involved simultaneously with demand limiting, a supervisory program must govern the controlling activities to resolve conflicts that may arise between strategies.

It is believed that after necessary modification the algorithms presented here can be implemented on actual hardware. 


\section{REFERENCES}

[1] Air Conditioning, Heating and Refrigeration News, June 21, 1982.

[2] Zilko, P.S., "Apply Demand Controls for Energy Conservation," Specifying Engr ., Feb. 1981, Pp. 74-77.

[3] IEEE, Standard Dictionary of Electrical and Electronics Terms, 2nd ed., edited by Frank Jay, IEEE, New York, 1977.

[4] Potomac Electric Power Co., "Understanding KW Demand," Energy Management Series, PEPCO, May 20, 1977.

[5] Shih, J.Y., "Energy Conservation and Building Automation," ASHRAE Tran8., Vol. 81, Part 1, Jan. 1975, pp. 419-435.

[6] Militello, P.G., "Concepts in Demand Control," Public Utilities Fortnightly, Aug. 1975, pp. 29-34.

[7] Pannkoke, T., "The Ups and Downs of Demand Limiting," Heating/Piping/Air Conditioning, Dec. 1976, pp. 25-30.

[8] Novak, W.J., "Saving Energy through Load Scheduling, Cycling and Shedding," Electrical Construction and Maintenance, Vol. 77, No. 4, April 1978 , Pp. $57-62$.

[9] Spethmann, D.H., "Electrical Energy Management," ASHRAE Journal, July 1981, pp. 31-35.

[10] Teed, R.H., "A Practioner Looks at Peak-Load Pricing," Public Utilities Fortnightly, Jan. 29, 1956, pp. 26-29.

[11] Carpenter, W.W., "The Energy Ratchet Rate Form," Public Utilities Fortnightly, Jan. 3, 1974, pp. 28-31.

[12] General Electric, "Manual of Demand Meters," General Electric, Publication GET-2327 C. 
[13] Potomac Electric Power Co., "Demand Measurement Instrumentation," Energy Management Service, June 24, 1977.

[14] Hurley, C.W., Kelly, G.E., and Kopetka, P.A., "Using Microcomputers to Monitor the Field Performance of Residential Heat Pumps," Nat1. Bur. of Standards, NBSIR 81-2285, June 1981.

[15] Tretter, S.A., Introduction to Discrete-time Signal Processing, John Wiley, N.Y., 1976.

[16] Quinn, G.C. and Knisley, J.R., "Controlling Electrical Demand," Electrical Construction and Maintenance, June 1976, pp. 43-52.

[17] May, W.B., "Time of Day Control and Duty Cycling Algorithms for Building Management and Control Systems," Nat1. Bur. of Standards, NBSIR 83-2713, 1983. 

APPENDIX A. Computer Program Listing of the Ideal Rate Method with Fixed Interval-DLRF

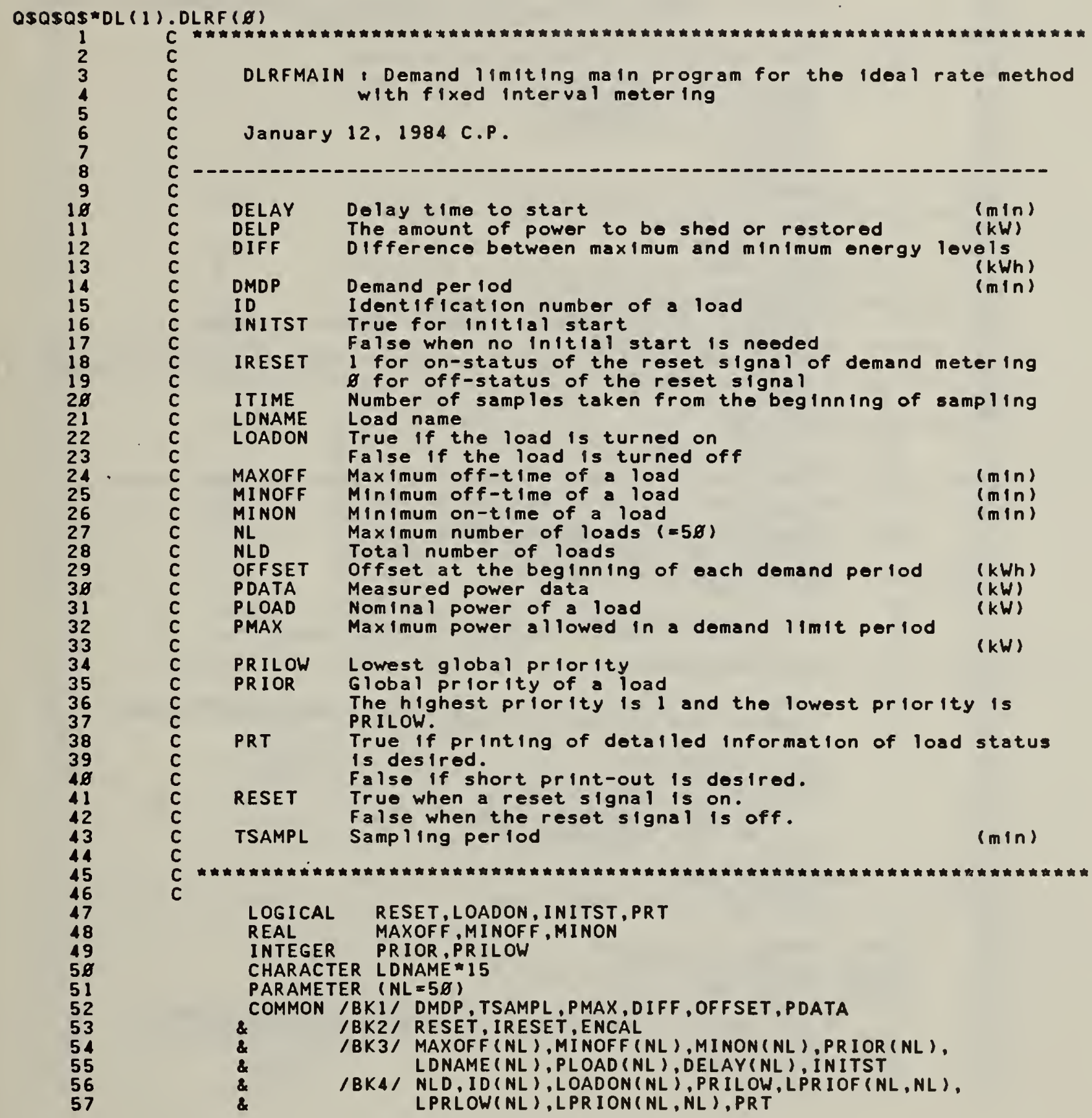




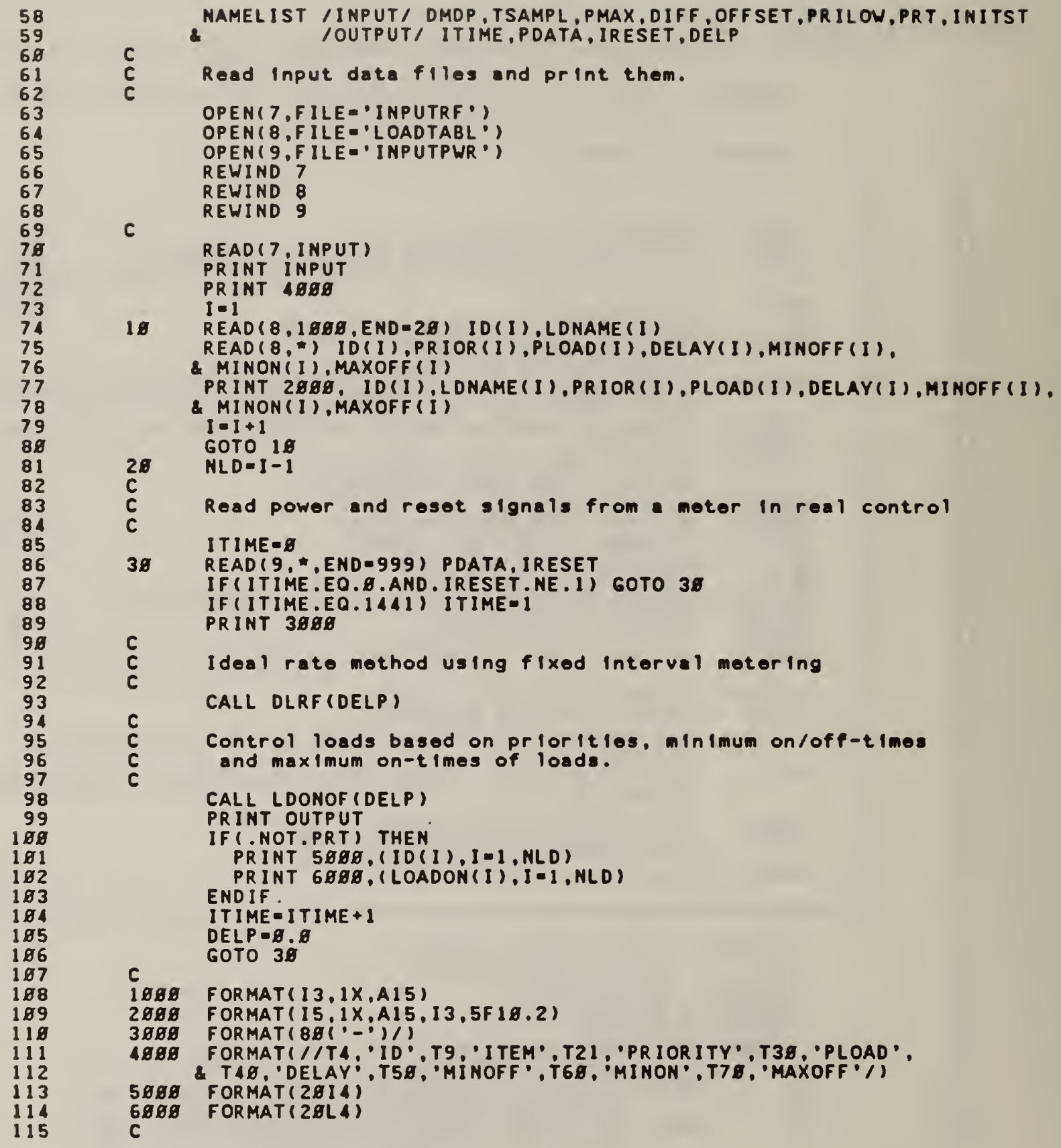




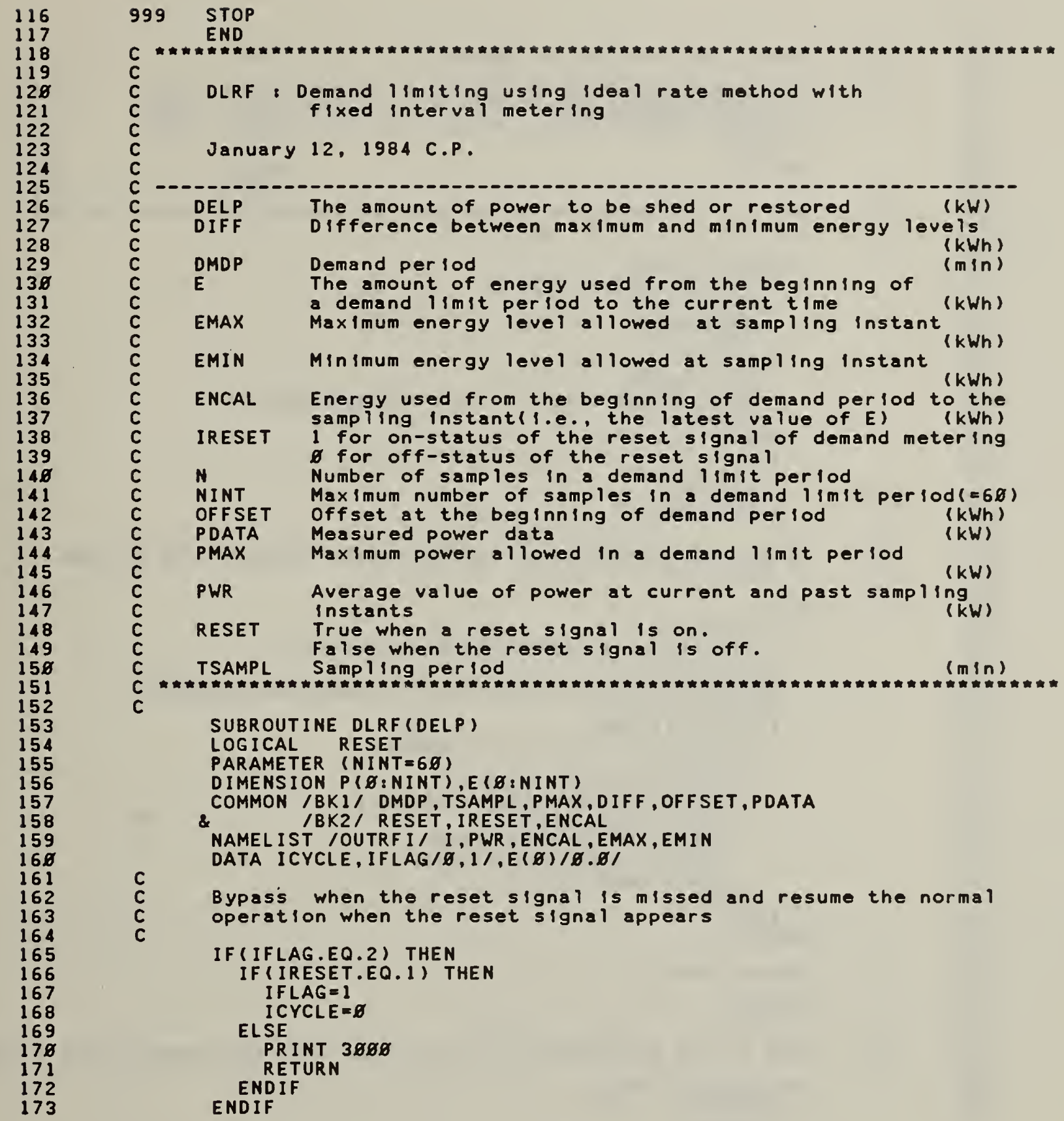


232

233

234

235
ENDIF

FORMAT $(/ 5 X, \cdots$ POWER TO BE SHED', F10.2, - 10. )

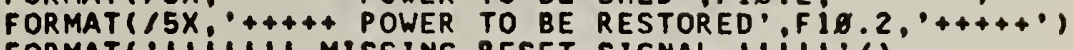
FORMATI IIIIII MISSING RESET SIGNAL I!!!, i,

RETURN

END 

APPENDIX B. Computer Program Listing of the Predictive Method with Fixed Interval - DLPF

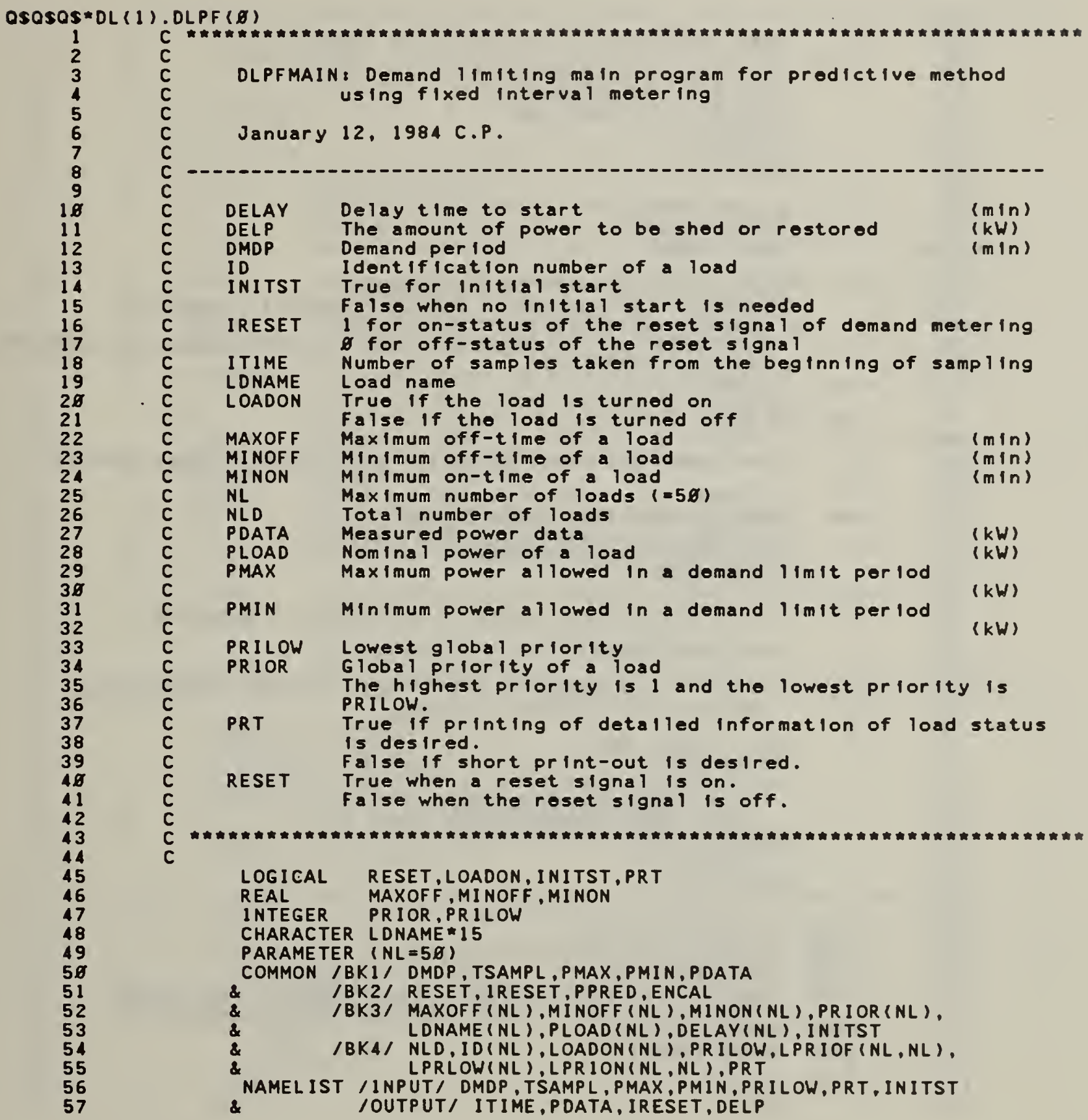




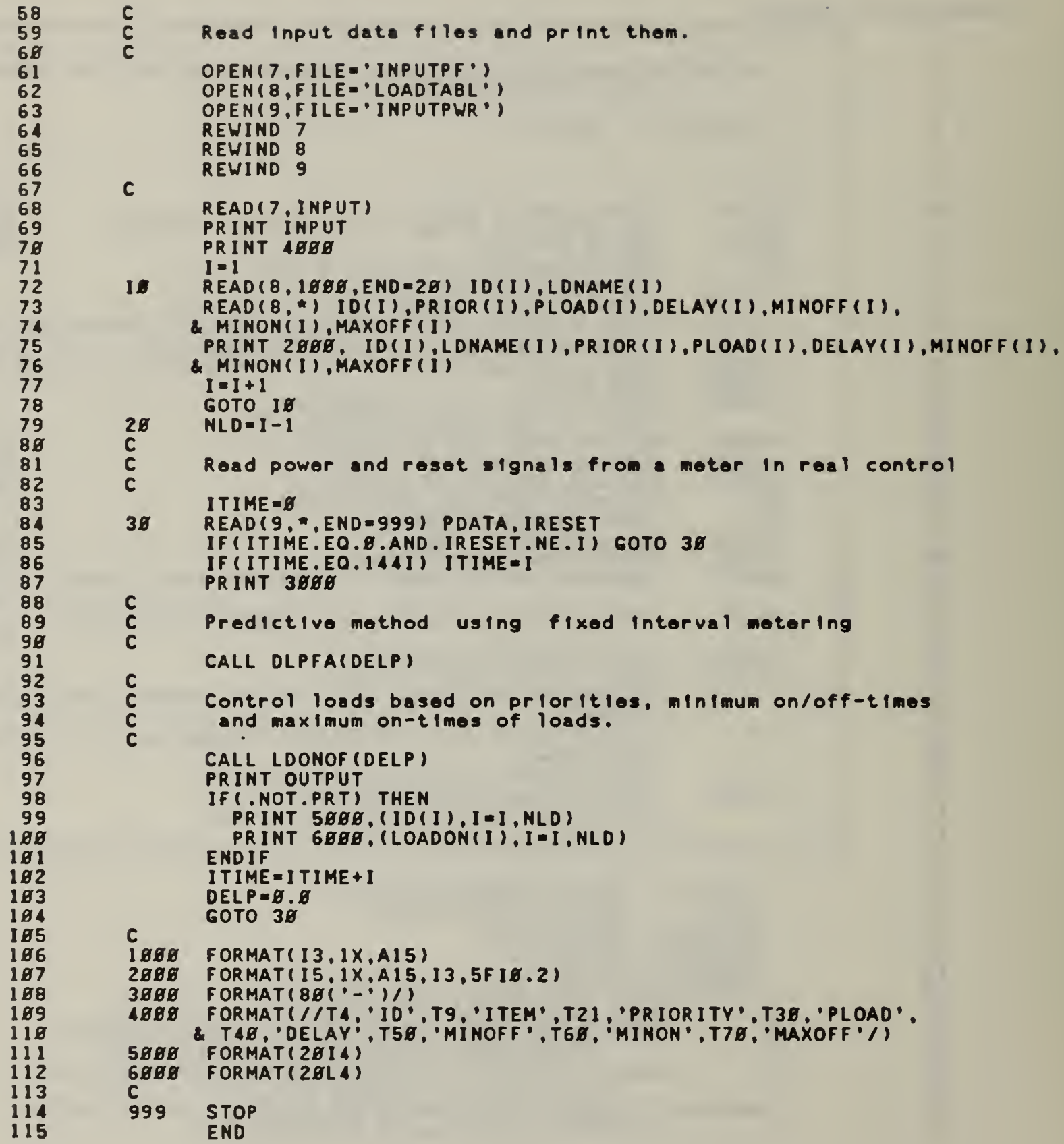




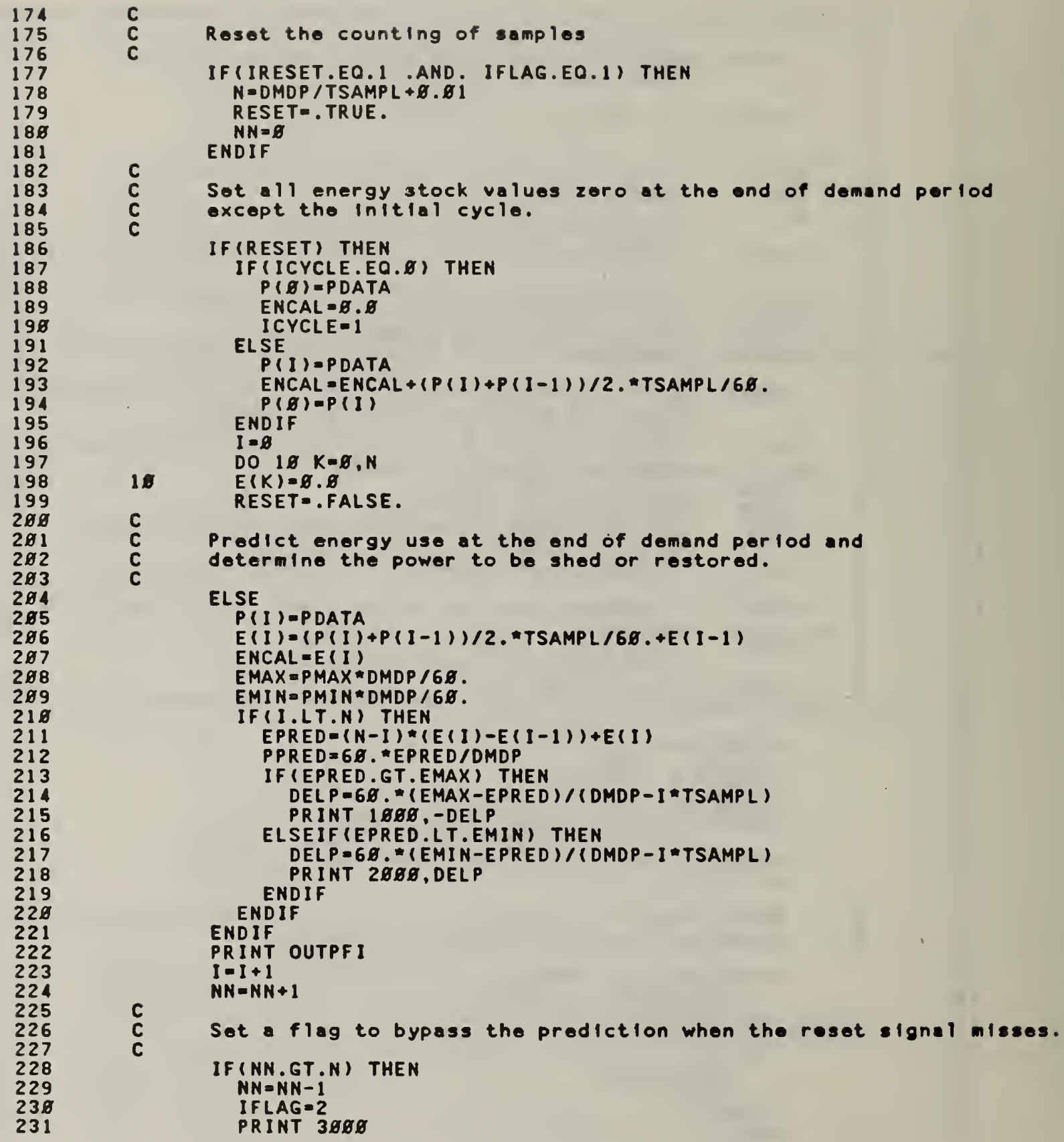




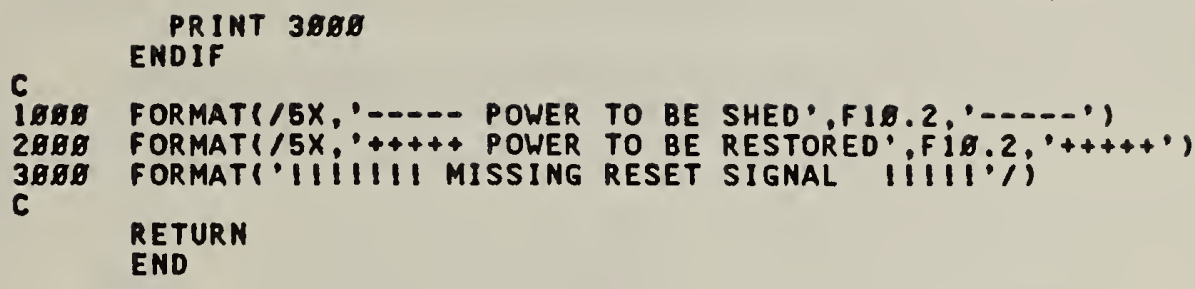



APPENDIX C. Computer Program Listing of the Predictive Method with Sliding Window - DLPS

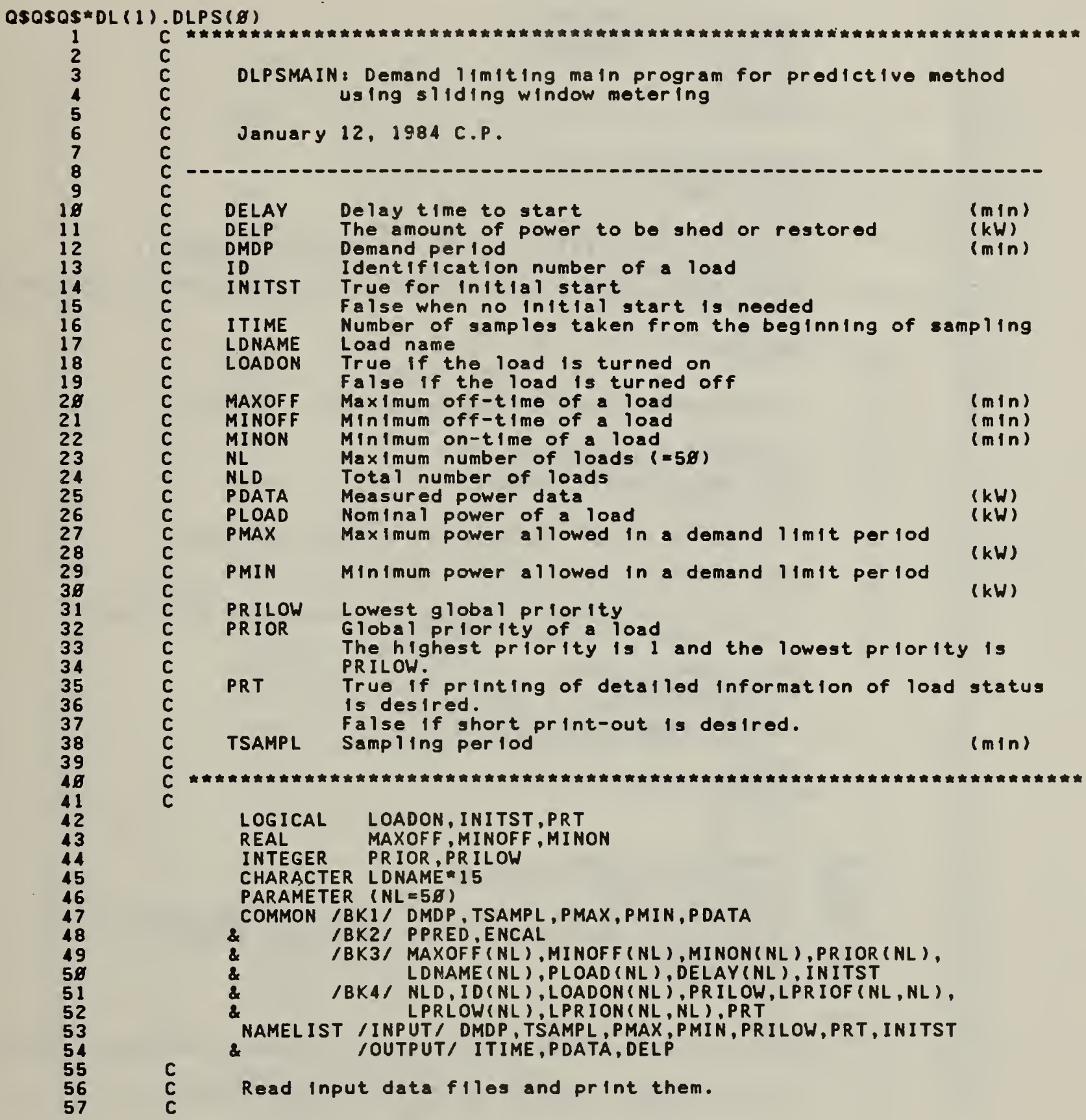




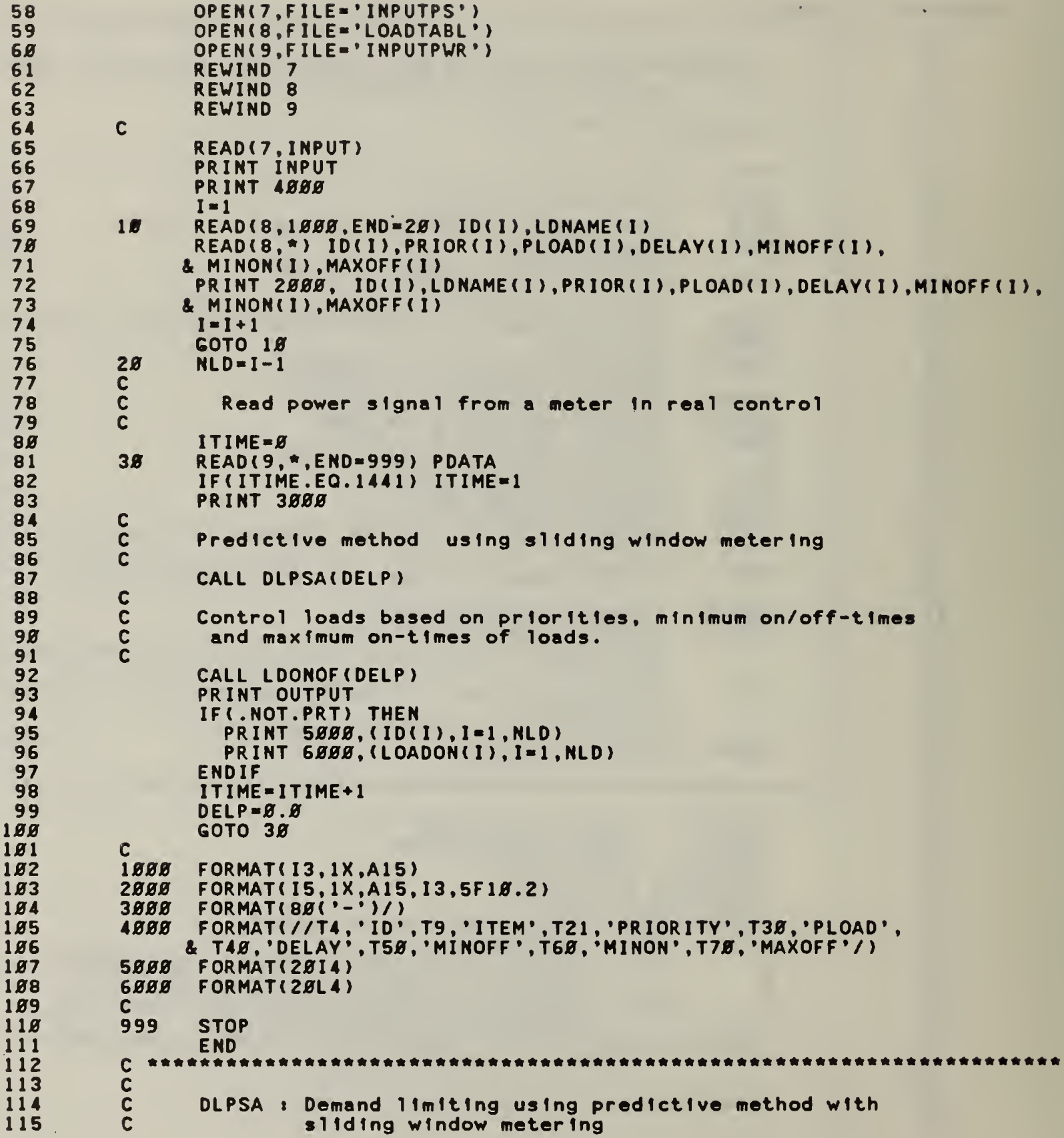


c

Shift back the regressor vector by one sample perlod DO $48 K=N-1,0,-1$

48

C ENDIF

18E8 FORMAT(/5X, -

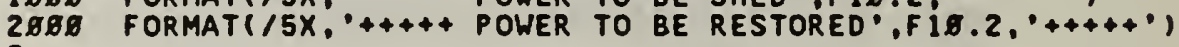

C

RETURN

END 
APPENDIX D. Computer Program Listing of the Instantaneous Rate Method - DLIS

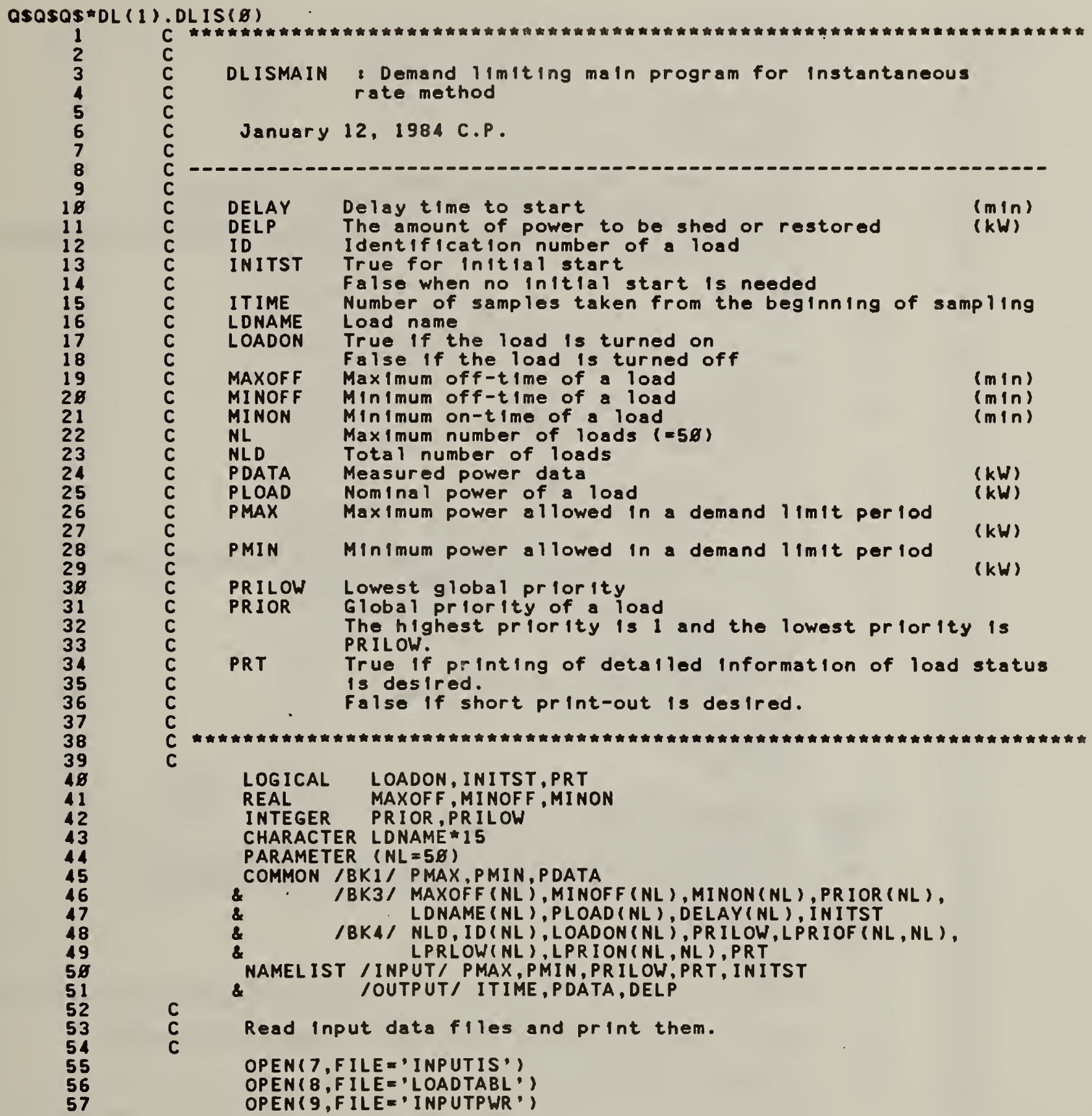




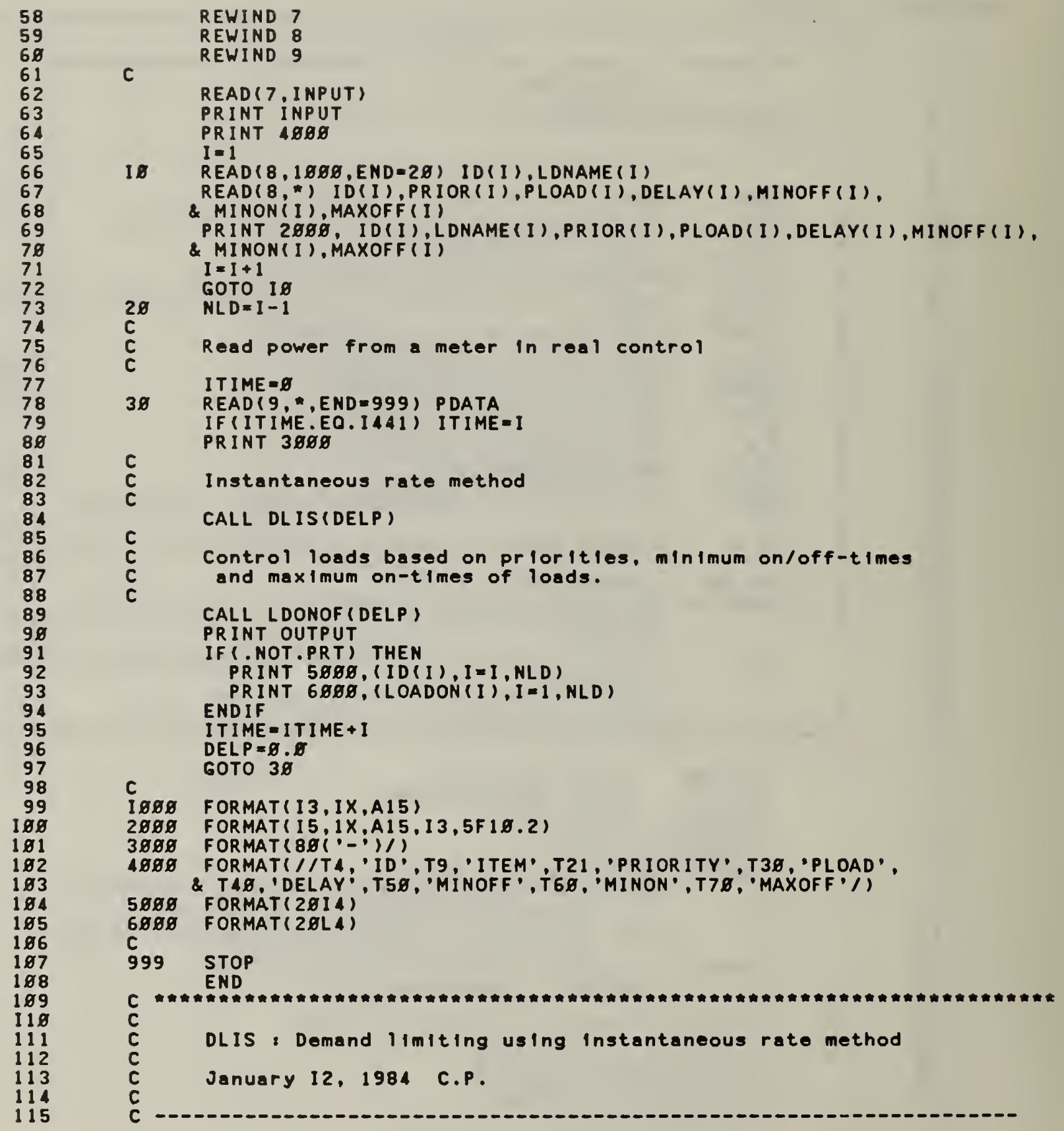




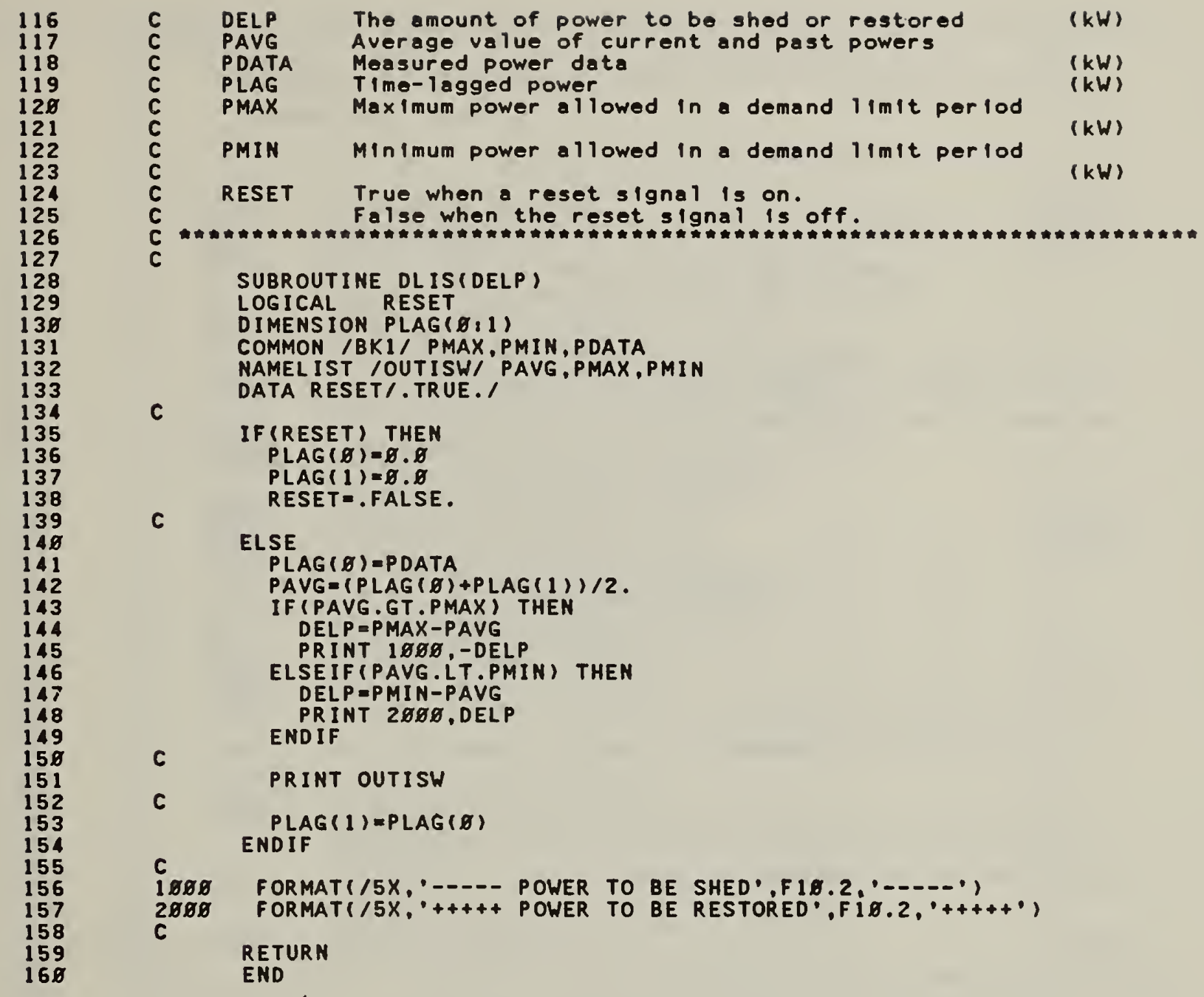


APPENDIX E. Computer Program Listing of the Predictive Method with Flexibility in Metering - DLPFS

OSOSOS\#DL(1).DLPFS(

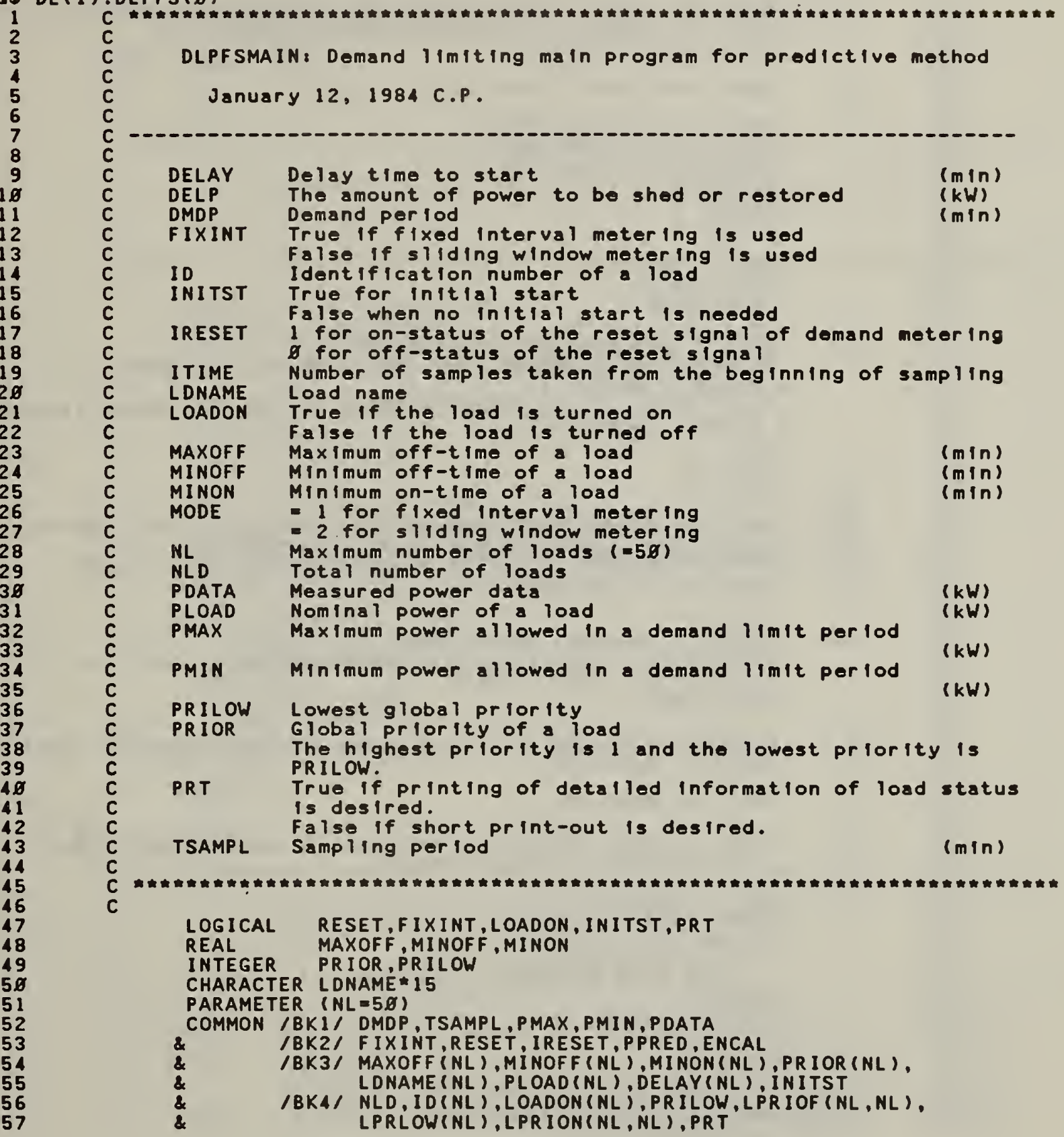




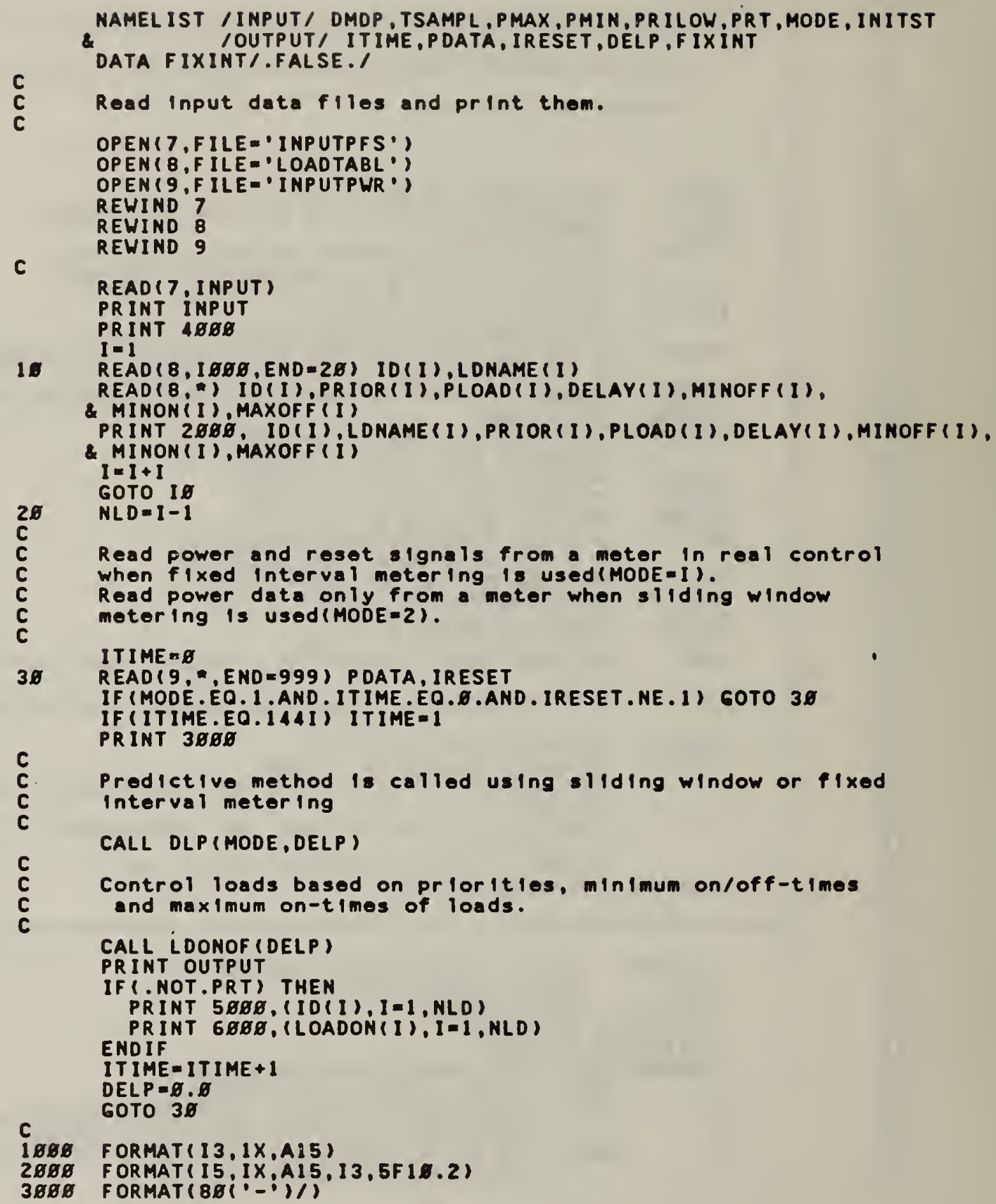




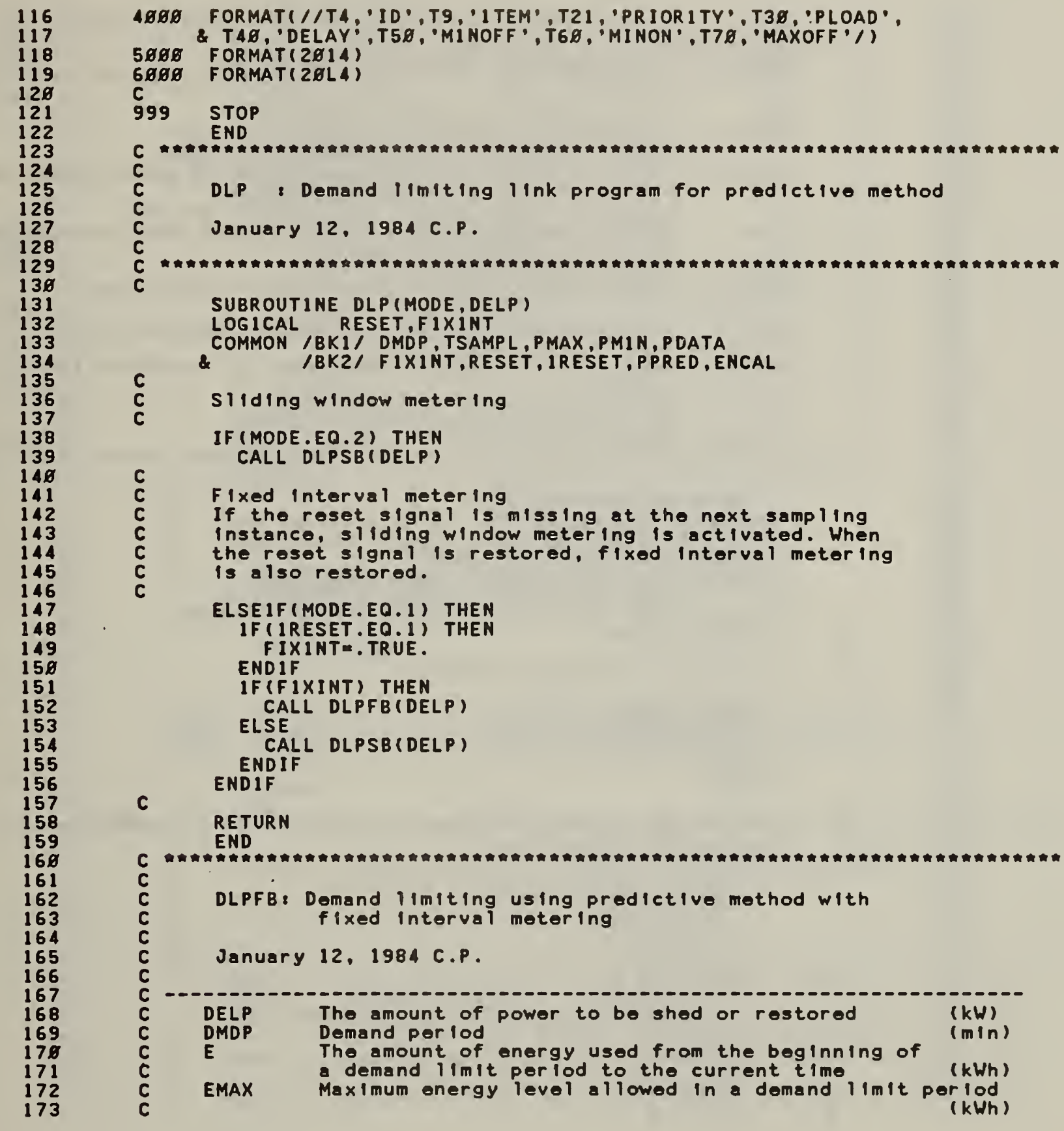




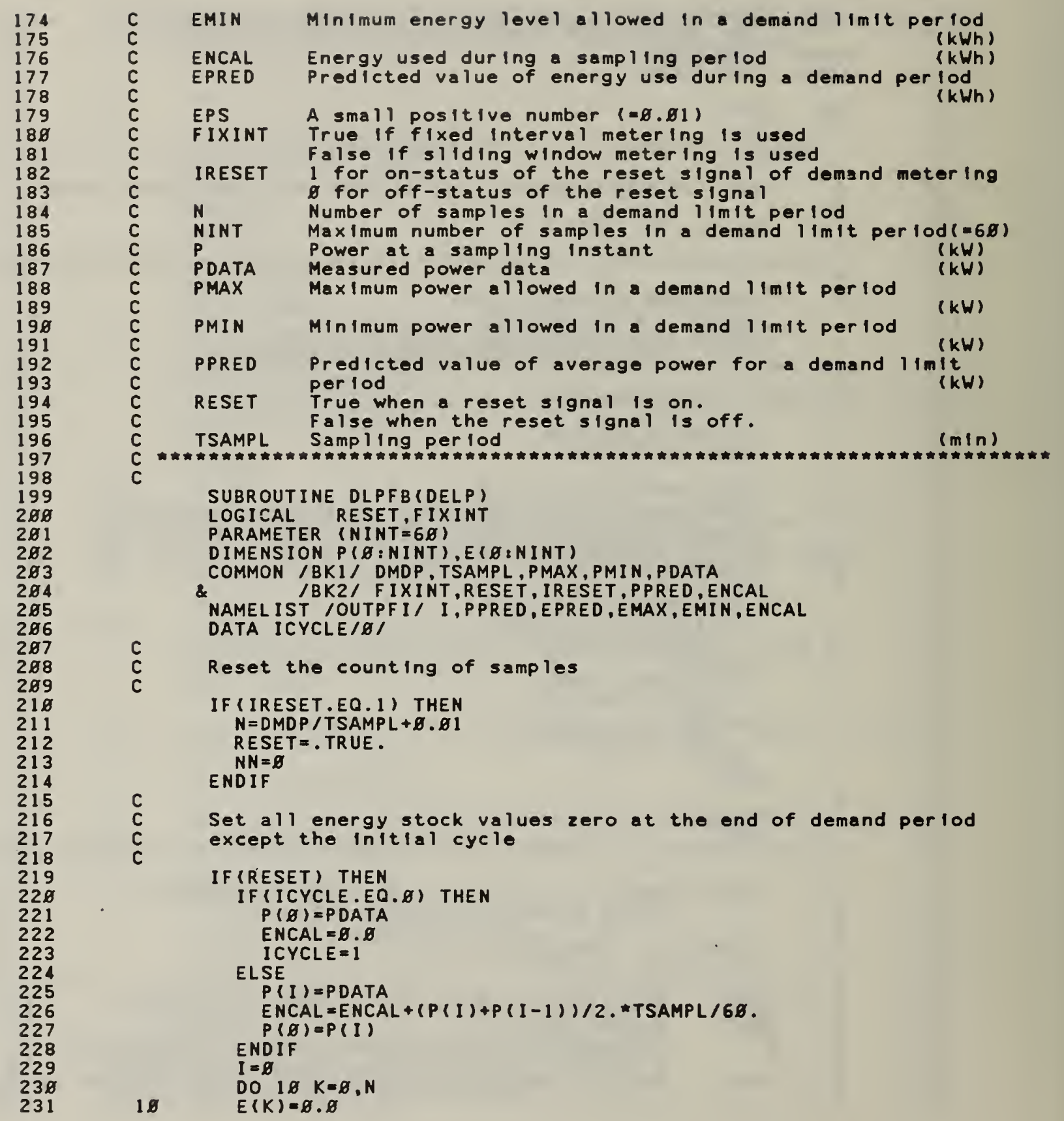




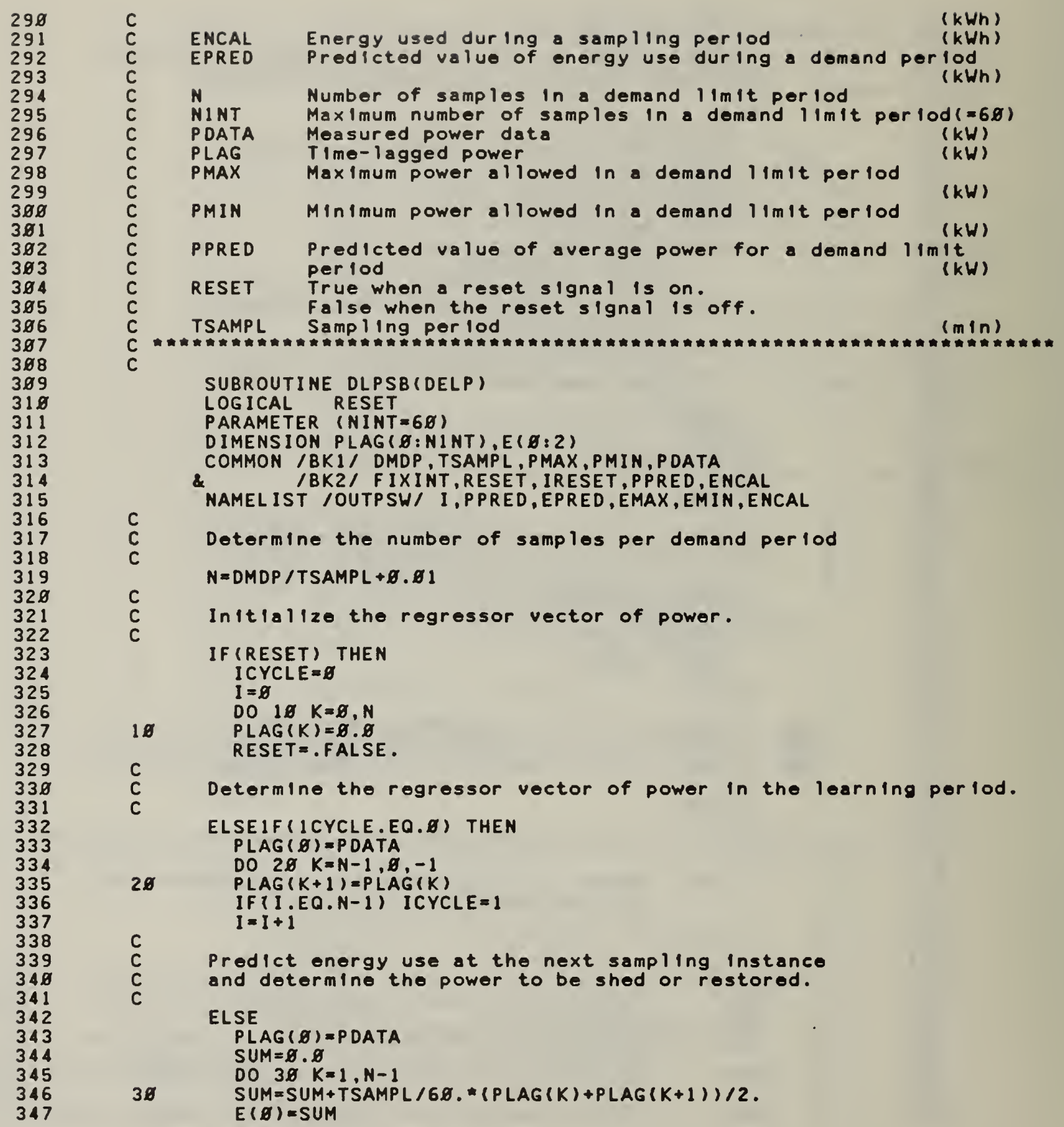


$E(1)=$ TSAMPL/6\%. $(P L A G(\theta)+P L A G(1)) / 2,+E(\theta)$

$E N C A L=E(1)$

$E(2)=2 * E(1)-E(g)$

EPRED=E( 2$)$

PPRED $=6 \%$. EPRED /DMDP

$E M A X=P M A X=D M D P / 6 \%$.

$E M I N=P M I N * D M D P / 6 \%$.

IF (EPRED.GT. EMAX) THEN

$D E L P=6 \%$. (EMAX-EPRED) /TSAMPL

PRINT 1 \%EO, -DELP

ELSEIF (EPRED.LT.EMIN) THEN

$D E L P=6 \%$. $(E M I N-E P R E D) / T S A M P L$

PRINT 2989. DELP

ENDIF

C

PRINT OUTPSW

c

Shift back the regressor vector by one anple perlod

00 40 $K=\mathrm{N}-1, \varnothing,-1$

48 PLAG $(K+1)=P L A G(K)$

C ENDIF

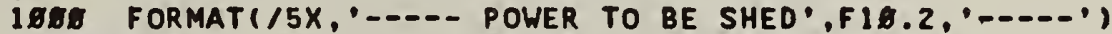

2989 FORMAT $\left(/ 5 X_{1},+++++\right.$ POWER TO BE RESTORED, Fi $\left.i .2, \cdot+++4+\cdots\right)$

C

RETURN

END 

APPENDIX F. Computer Progran Listing of the Load Control Algorithm - LDONOF

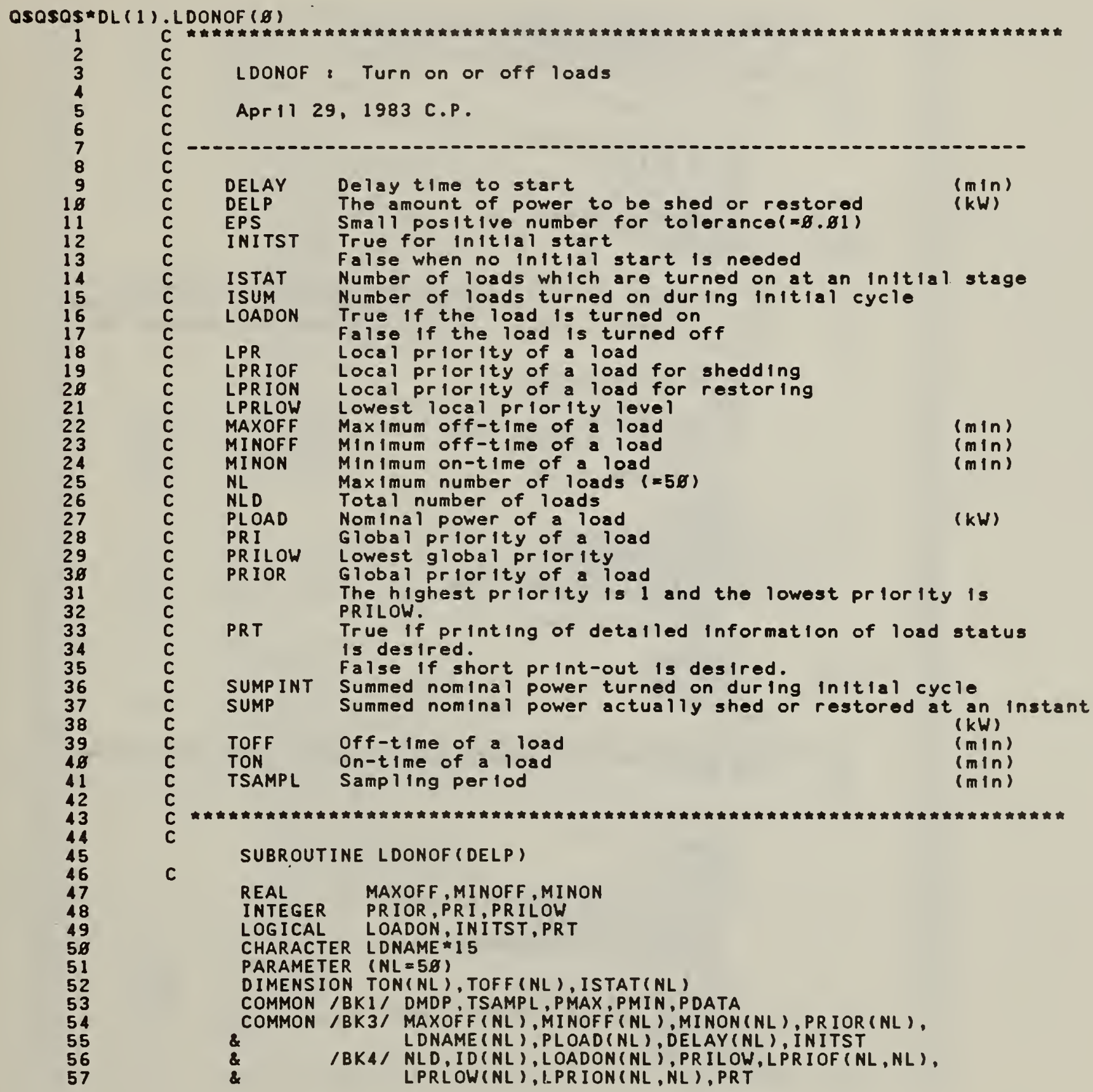




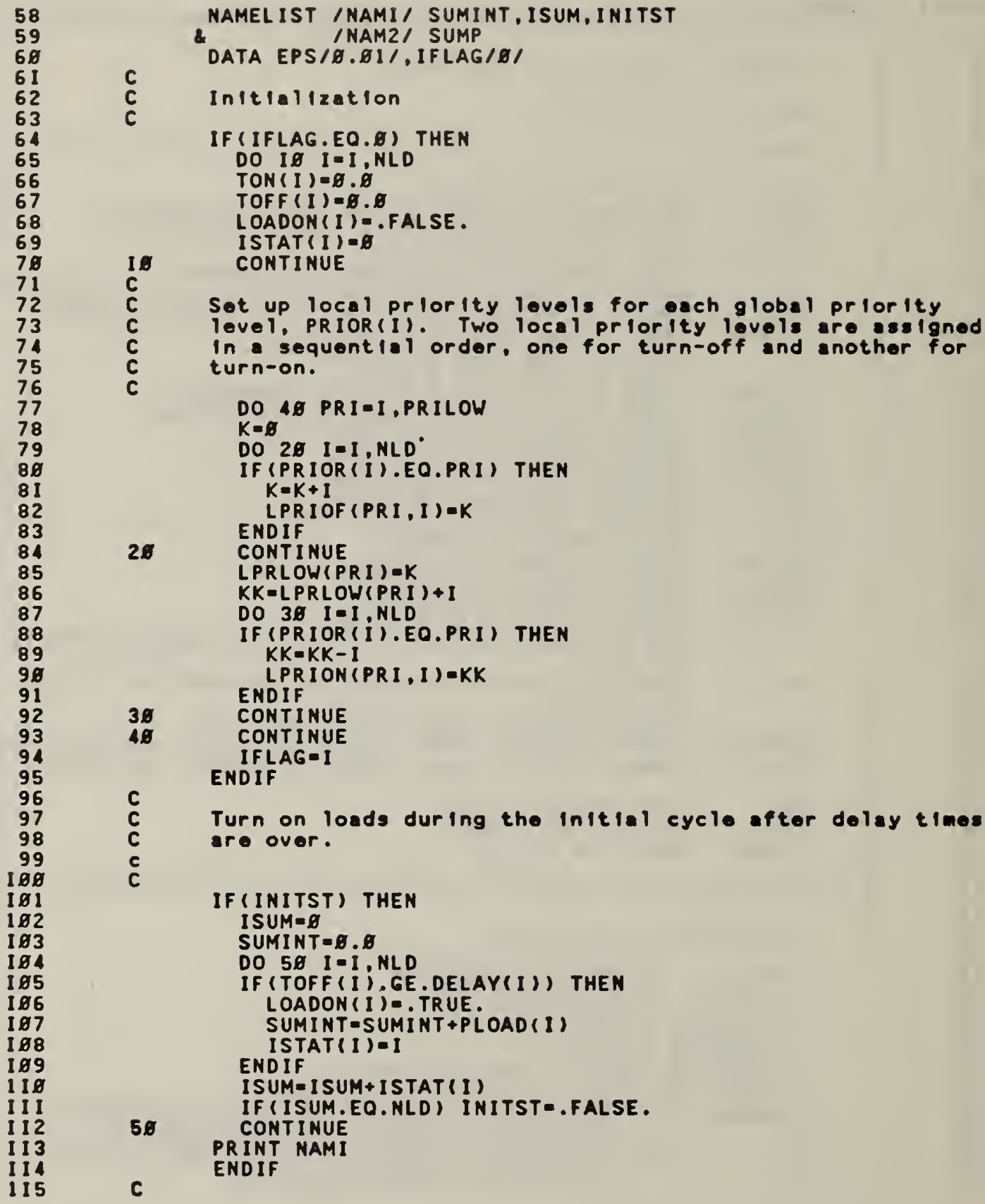




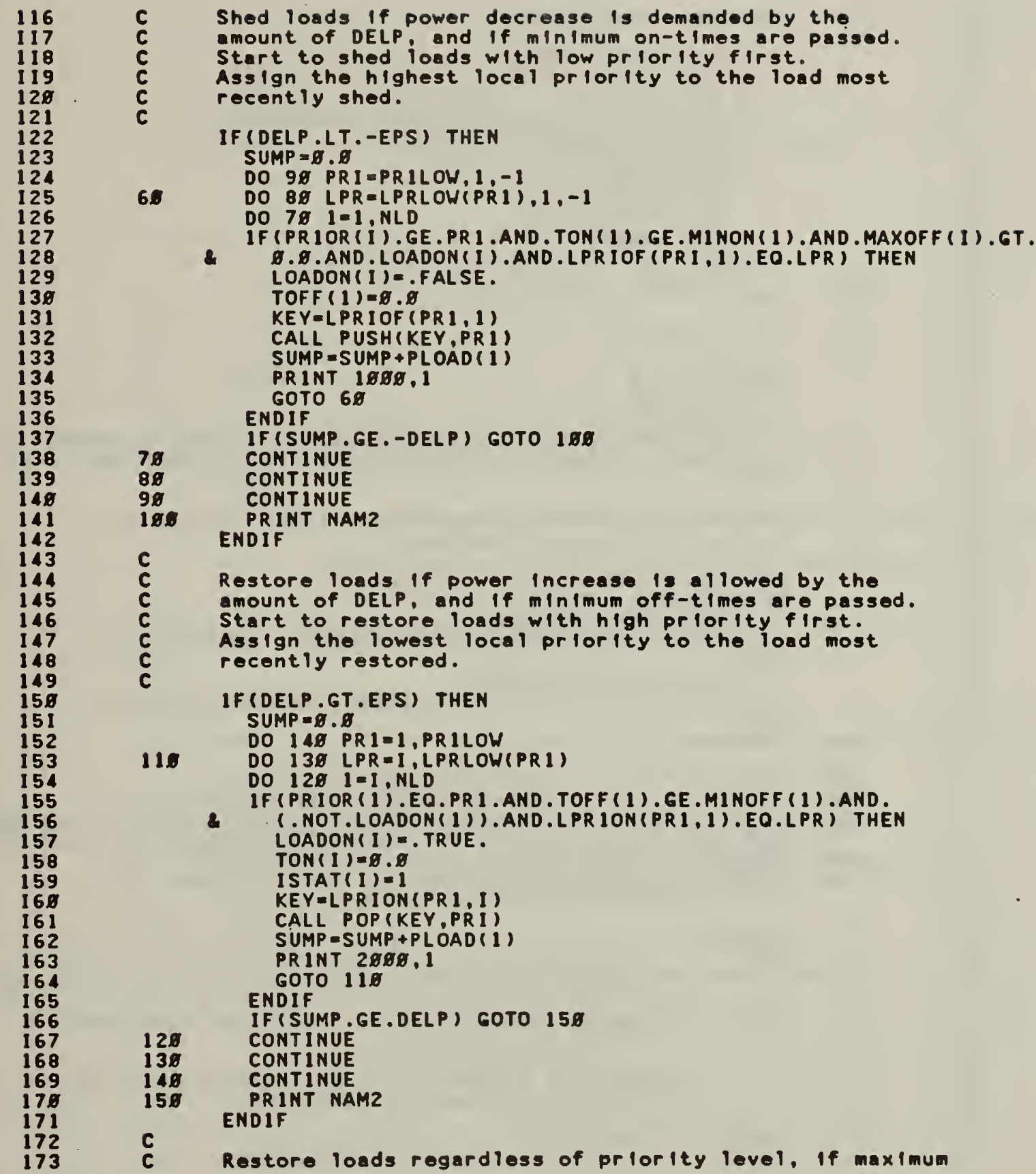




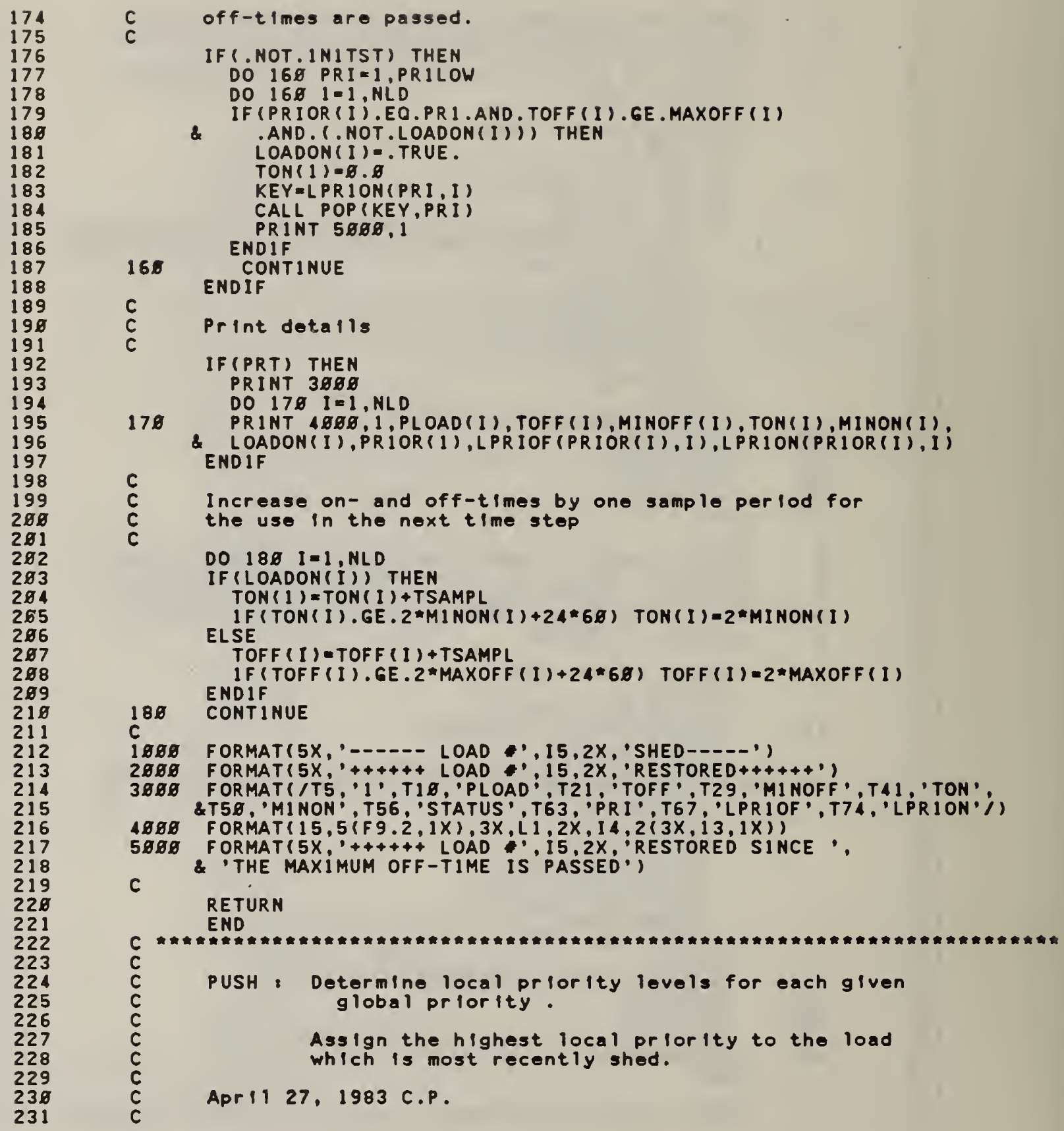



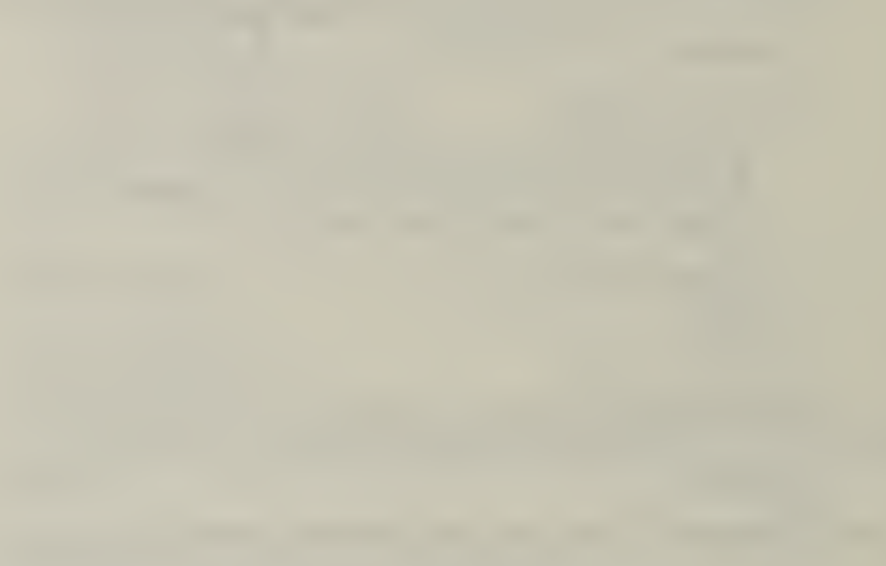

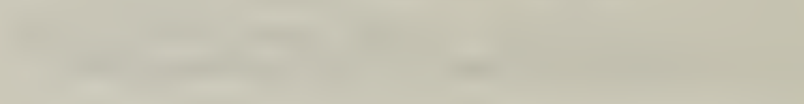


APPEXDIX G. Open-Loop Computer Simulation

For illustration purposes, a computer simulation was performed under an openloop condition and is presented in this appendix. The open-loop assumption cannot be applied in actual load control condition, employing demand limiting control algorithms. Without feedback, the effects of load shedding or restoring are not realized in the control action. The selected algorithm for the simulation was the predictive method with flexibility in metering (either fixed interval or sliding window metering) as described in section 4.5 . Accordingly, the computer programs given in Appendiz $\mathrm{E}$ and Appendiz $\mathrm{F}$ were used. Most numerical values of input data were arbitrarily selected but some of the values for average power requirement were extracted from the work by May.* Some extremely large and small numerical values were specified as input data in order to check the capability of the computer program.

The main program, DLPFSMAIN, in Appendix E calls three input files as follows:

$\begin{array}{cc}\text { Logical Unit } & \text { File Name } \\ 7 & \text { INPUTPFS } \\ 8 & \text { LOADTABL } \\ 9 & \text { INPOTPWR }\end{array}$

The format used by the file, INPUTPFS, is an input format for the NAMELIST statement of Fortran 77 in a Sperry $1100 / 82$ computer. Since this format is machine-dependent, a Fortran user's manual should be consulted if other

*W. B. May, "Analysis of Data from the Energy Monitoring and Control System at the Norris Cotton Federal office Building," Nat1. Bur. of Standards, NBSIR $81-2358,1981$. 
computers are employed. If desired, the main program, DLPFSMAIN, may be modified to read the information in the INPOTPFS file interactively. The INPUTPFS file contains the following:

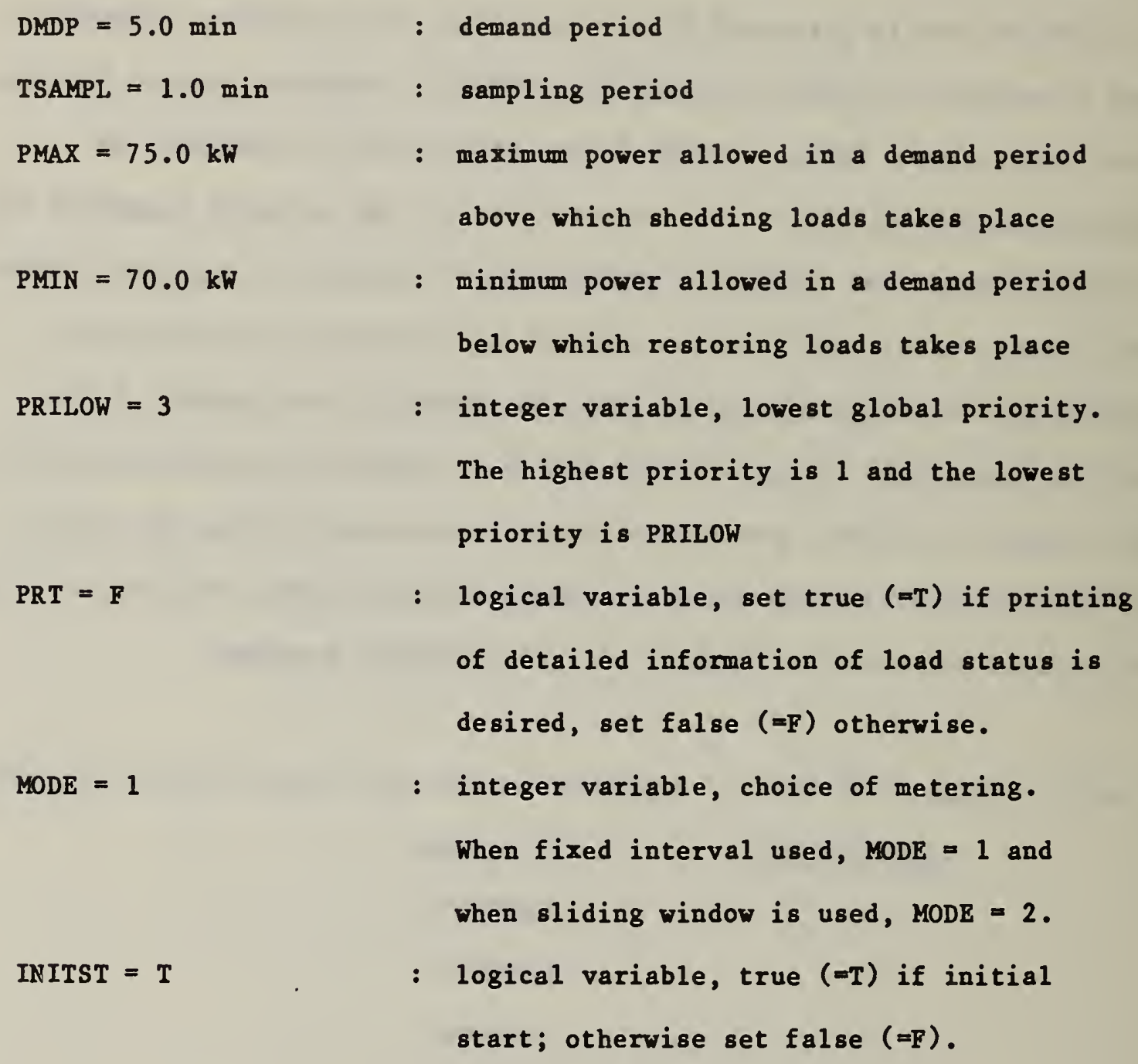

The file, LOADTABL, is needed for the load control routine, LDONOF, that is listed in Appendix F. The file comprises the following items for each load: ID $=001$ : integer variable, load identification number LDNAME = NORMAL LIGHT \#1: description of a load, up to 15 characters 


$$
\begin{aligned}
& \text { PRIOR }=2 \\
& \text { : integer variable indicating the global } \\
& \text { priority of a load. The lower the number } \\
& \text { the higher the priority, and vice versa. } \\
& \text { PLOAD }=5.974 \mathrm{~kW} \quad \text { : nominal average power of a load } \\
& \text { DELAY }=0.0 \mathrm{~min} \quad \text { : delay time for starting at the initial } \\
& \text { period } \\
& \text { MINOFF }=0.0 \mathrm{~min} \\
& \text { : minimum off-time of a load. Only after this } \\
& \text { off-time, the load may be restored. } \\
& \text { MINON }=0.0 \mathrm{~min} \\
& \text { : minimum on-time of a load. Only after the } \\
& \text { on-time passes the minimum on-time, the load } \\
& \text { may be shed. } \\
& \text { MAXOFF }=1440.0 \mathrm{~min} \quad \text { : maximum off-time of a load. If the load is } \\
& \text { maintained off more than the time period } \\
& \text { specified by MAXOFF, restoring the load } \\
& \text { occurs automatically. Assignment of } \\
& \text { highest number }(=1440) \text { prevents automatic } \\
& \text { restoring. }
\end{aligned}
$$

The values given above are the values for the first load in the file, LOADTABL, in this appendix. For each load, two lines of data are needed such as shown below:

lst line: ID, LDNAME

2nd line: ID, PRIOR, PLOAD, DETAY, MINOFF, MINON, MAXOFF (free format)

The instantaneous power, PDATA, is actually measured at each sampling instant in a real control environment. In this open-loop simulation, the instantaneous power is not measured, but specified arbitrarily. The file, 
INPOTPWR, contains the instantaneous power, PDATA, and a reset signal, IRESET. PDATA has a unit of $\mathrm{kW}$, and IRESET is an integer, either 0 or 1 . Presence of the reset signal from the utility's meter is indicated by IRESET $=1$. PDATA and IRESET have a free format in the INPUTPWR file.

Important simulation output data are:

DELP: the amount of power to be shed or restored

LOADON: logical variable. True $(=T)$ if the load is turned on and false $(=F)$ if off. Using a supporting program, this logical value may be translated into a binary code and used as input to actual hardware controls.

Printout of $\mathrm{I} / 0$ operation for the simulation is included in the following page 8. 
QSOSOS*INPUTPFS(1)
1
2

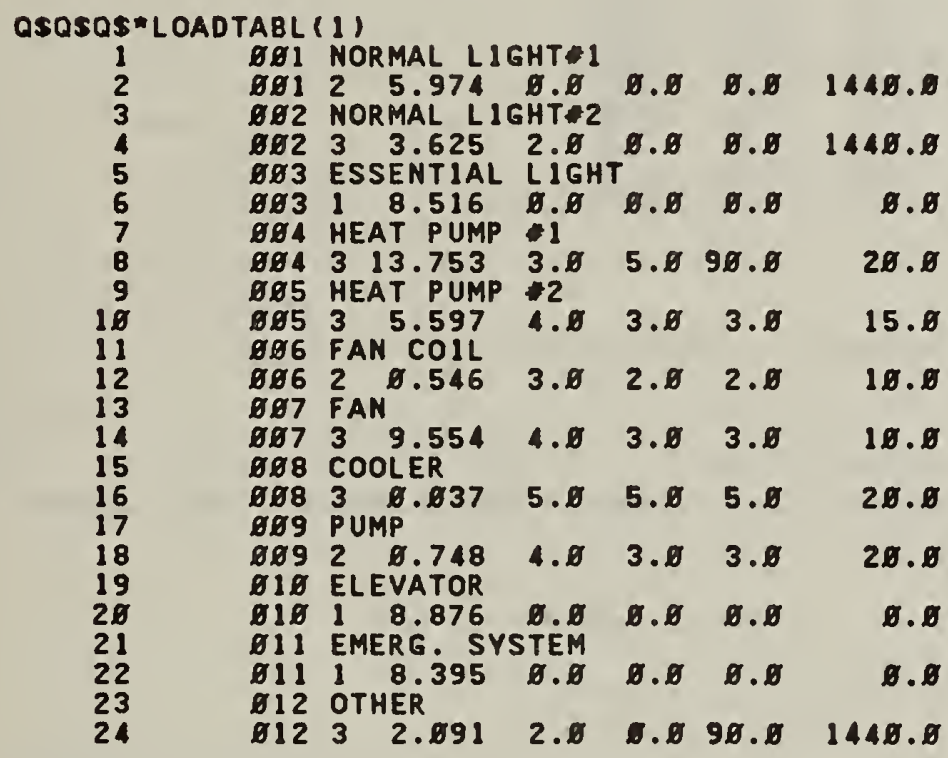

OSOSQS 1 NPUTPWR (1)

$31.76 \mathscr{E}$

$31.76 \%$

$31.76 \quad 8$

$31.76 \%$

$31.76 \varnothing$

31.761

$31.76 \%$

$37.48 \%$

51.780

$67.68 \%$

67.72 .1

$67.72 \%$

$67.72 \%$

67.758

$67.08 \%$

75.

$68.08 \%$

70.000

75.00

6. $.0 \%$ D

$7 \% .081$

75.808

8. 8.8

85.80

60.008

$5 \% .001$

$8 \% .00 \%$

48. 00

5. 0.00

67.000

80.00

40.00 

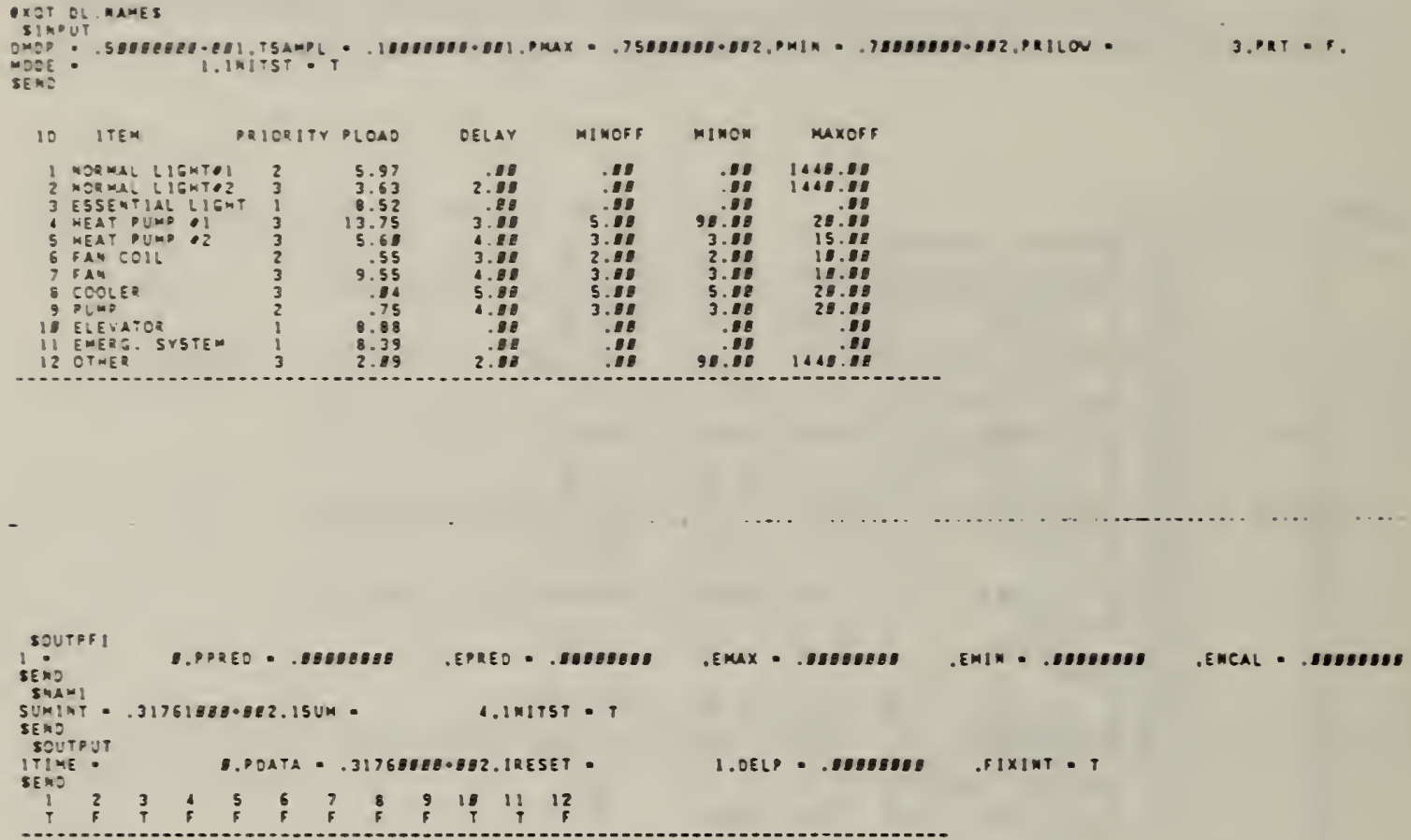
…... LOAD: , QESTOREO......

$\because \ldots .:$ LOAD: TOAO T RESTOBEO.......

SUMAK? .15899880 .882

SEND

STIME:

$$
\text { 3.PDATA - .5178EAEB.8B2.JRESET - }
$$

S. DELP . .74063ES1.802.F1X1NT P

\begin{tabular}{cccccccccccc}
\hline & 2 & 3 & 4 & 5 & 6 & 7 & 9 & 9 & 18 & 11 & 12 \\
1 & $T$ & $T$ & $T$ & $T$ & $T$ & $F$ & $T$ & $T$ & $T$ & $T$
\end{tabular}

SOPT... PONER TO BE RESTOREO $119.53 \ldots$.

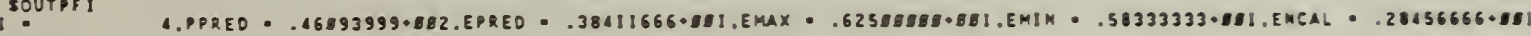
SEMD

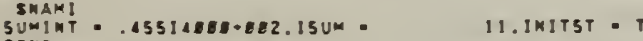

3 SND

SMAMz

SUMP. . Asegeso

STMTPUT

ITIME.

SEMO

A.POATA - .6768EG8B-8B2.1RESET

E.DELP - .119338E8.503.FIXINT - T

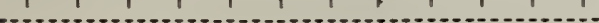

SOUTPFI

$\sin 0$

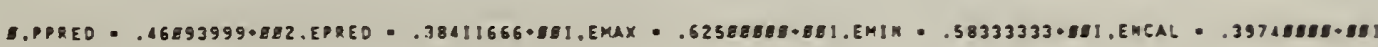

$\operatorname{SinN}$

SUKINT . .45531808.882.15UM. $12.1 \times 1 T 5 T \cdot F$

SOUTPUT

ITIME.

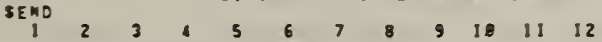

3.PDATA - .67728BE8.882.1RESET.

1.DELP - .QBEEE8E . .IXIKT -

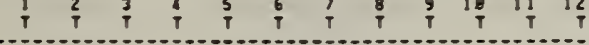

..... POVER TO BE RESTORED $2.85 \ldots \ldots$

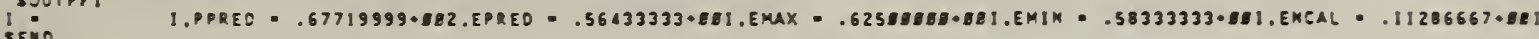

sump.

SEMD

SOUTPUT

SEMD

B. OELP. .2858B888.8B1, FIXIKT. T

$\begin{array}{llllllllllll}1 & 3 & 5 & 5 & 7 & 8 & 9 & 18 & 12\end{array}$

T T T T T T T T T T T T T T

SOUTPË POVER TO 8 E RESTOREO $3.89 \cdots \ldots$...

TEKO

SMMM?

SEMP

SETHT

ITIME.

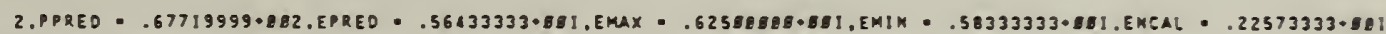
- 9868888

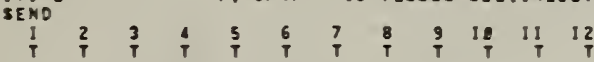

7.POATA - .67728E88.882.1RESET

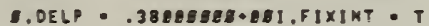

SOUTPF. POVER TO BE RESTORED - 5.68....

SOUTPFI 3.PPRED - .67728998.882.EPRED - .56448833.881.EMAX - .62586888.891.EMIK - .583333333.881.EMEAL - .33862588.98I

SNMAMz

SUMP. .8888888

SOUTPUT

ITIME

B.poAta - .g775gegg.gez.1Re5et -

C.DELP - .56775816.8E1.51X1KT. T

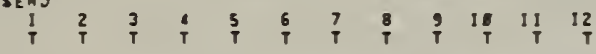

SOUTPFi POVER TO BE RESTOREO $12.88 \cdots . .$.

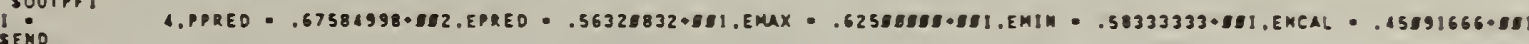
SEMD

SKAMz

SUKB.

SOMTPUT

SOUTPUT

ITIME

9.POATA - . GTERESEg.BEz,IRESET -

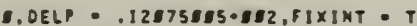

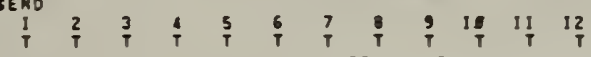

soutpF

SEMO

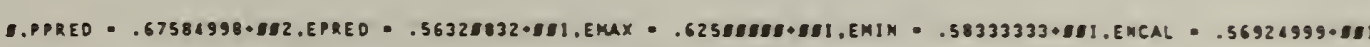

SOUTPUT

ITIME

10.POATA - .75EEgEgB.EBz.18ESET

1.0ELP - .eseseges

.FIXINT - T

$\begin{array}{cccccccccccc}1 & 2 & 3 & 4 & 5 & 6 & 7 & 9 & 9 & 19 & 11 & 12 \\ 1 & 1 & 1\end{array}$ 


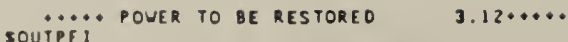

SOUTPH+ FOUER TO QE RESTORED $7.5 \% \cdots \cdots$

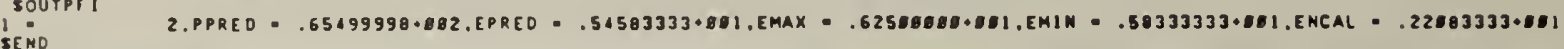

SHAH2

SUMP -.00008080

SE ND

SOUTPUT

ITIME

$\begin{array}{cccccccccccc}S E N O & 2 & 3 & 4 & 5 & 6 & 7 & 8 & 9 & 18 & 11 & 12 \\ 1 & T & T & T & T & T & T & T & T & T & T & T\end{array}$

ש.DELF. .31249997-081,F1X1NT - T

SOUTPFi. POWER to BE RESTOREO . He.....

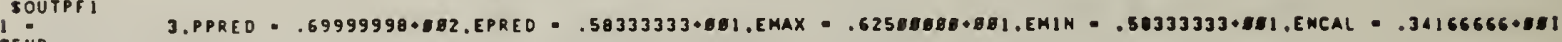

SEND

SOUTPUT

ITIME

\begin{tabular}{lllllllllllll}
1 & 2 & 3 & 4 & 5 & 6 & 7 & 8 & 9 & 10 & 1 & 1 & 1 \\
\hline & $T$ & $T$ & $T$ & $T$ & $T$ & $T$ & $T$ & $T$ & $T$ & $T$
\end{tabular}

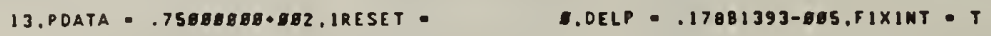

SOUTPFi POUER TO QE RESTOREO $18.88 \ldots . .$.

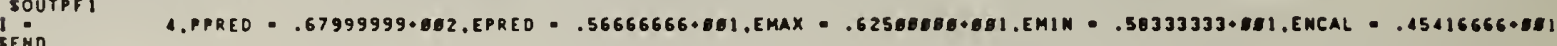

SEND

SUMP 2 . .

SUMP

SEND
SOUTPUT

ITIME.

SEND

\begin{tabular}{cccccccccccc}
\hline & 2 & 3 & 4 & 5 & 6 & 7 & 8 & 9 & 10 & 11 & 12
\end{tabular}

0.0ELP. . 100808010002.FIXINT. T

SOUTPF 1

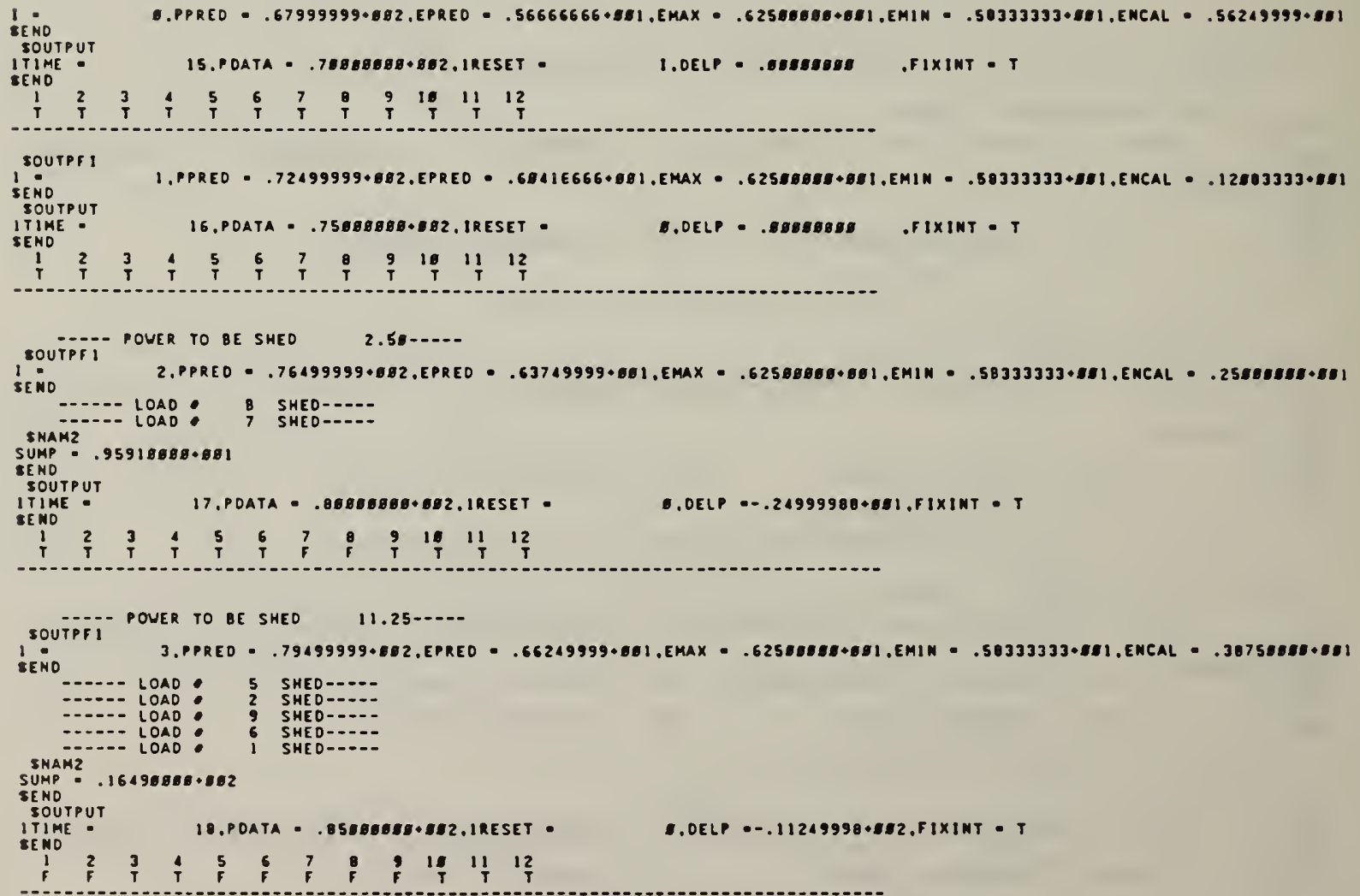




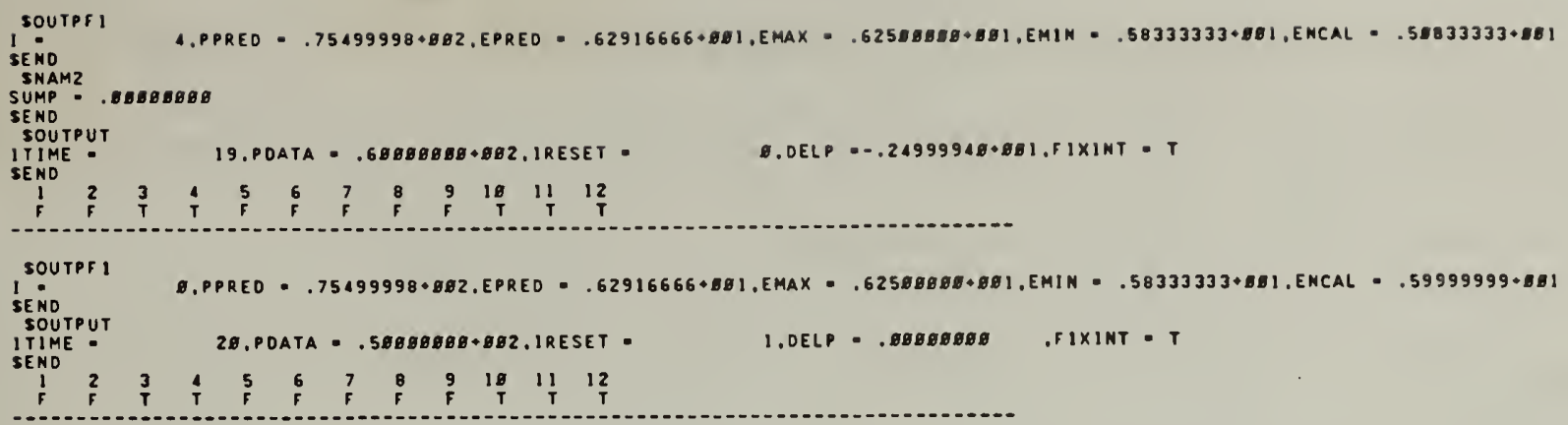

SOUTPF

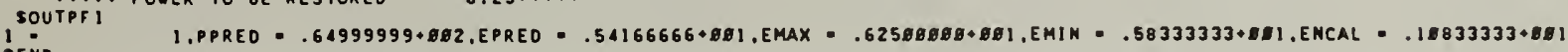

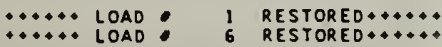

SNAM2 651999990991

SUMP

SOUTPUT

ITIME.

SEND

21.POATA - .88EOEOEg+8E2.1RESET -

G. OELP $=.62588883+081 . F 1 \times 1 N T=T$

$\begin{array}{cccccccccccc}1 & 2 & 3 & 4 & 5 & 6 & 7 & 8 & 9 & 18 & 11 & 12 \\ T & F & T & T & F & T & F & F & 5 & T & T & T\end{array}$

\#.... POVER TO 8 E RESTORED $15.004+4+0$

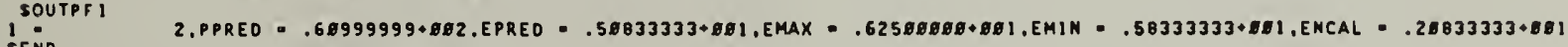

LOAD 9 RESTORED

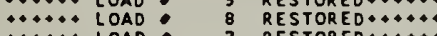

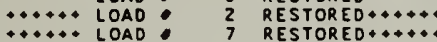

\#... LOAD: 5 RESTORED+*.+.

SNAM2

SUMP $.19561000 \cdot 802$

SEND

SOUTPU

IT IME

22,PDATA - . $9890989+962$, IRESET

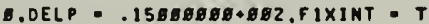

$\begin{array}{llllllllllll}i & 2 & 3 & 4 & 5 & 6 & 7 & 8 & 9 & 10 & 11 & 12 \\ T & T & T & T & T & T & T & T & T\end{array}$
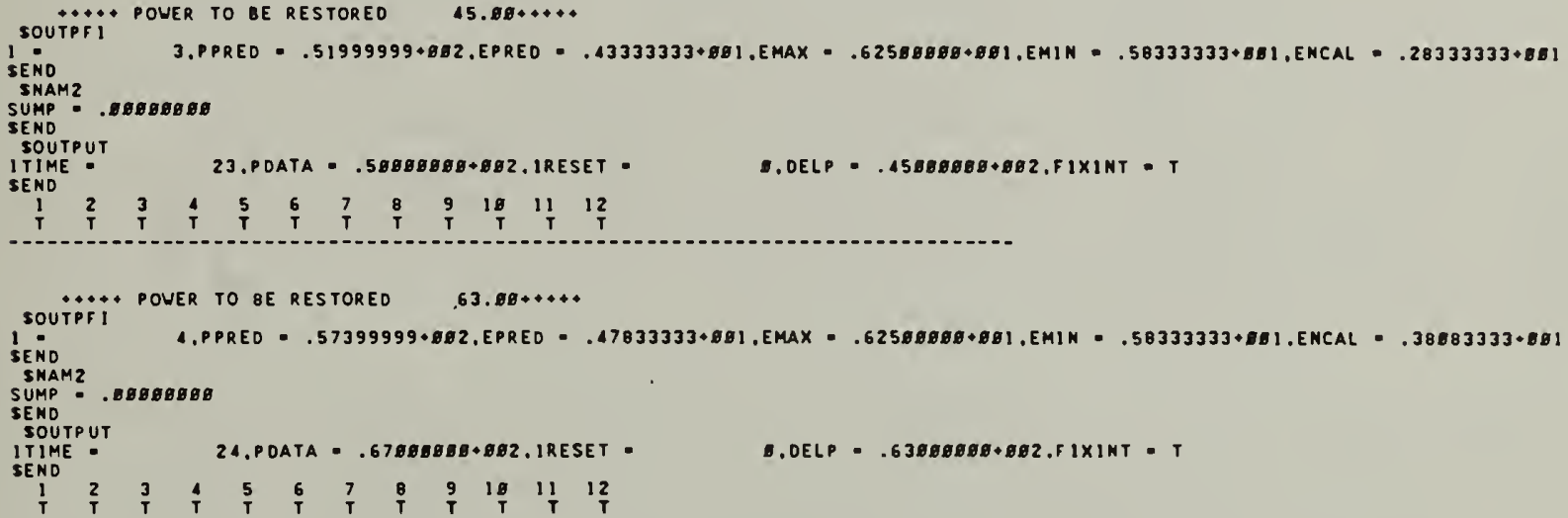

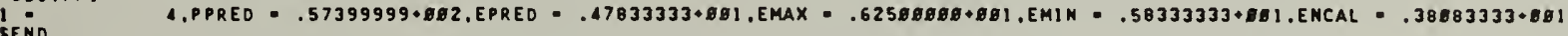

SUMP?

SEND

SOUTPUT

ITIME

$\begin{array}{cccccccccccc}\text { SEND } & 2 & 3 & 4 & 5 & 6 & 7 & 6 & 9 & 18 & 11 & 12 \\ 1 & T & T & T & T & T & T & T & T & T & T & T\end{array}$

G.DELP - .638980880082,F $1 \times 1 \mathrm{NT} \cdot T$

SOUTPFI

SEND

SOUTPUT

1 TIME.

$\begin{array}{cccccccccccc}\text { SEND } & & & & & & & & \\ T & T & 3 & 4 & 5 & 6 & 7 & 8 & 9 & 18 & 11 & 12\end{array}$

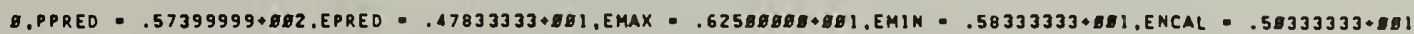
25,PDATA - .8EOEBEGQ+EE2,1RESET -

1, OELP. . .

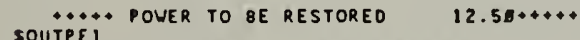

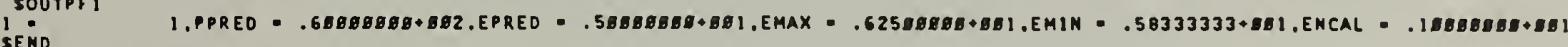

SEND

SNAM2
SUMP .
SEgOEOEg

SEND

SOUTPU

1 IIME

26, POATA - . AEEEEQEE+ OE2, IRESET -

D.DELP - .12586000+BE2,FIXINT. T

\begin{tabular}{llllllllllll}
$T$ & 2 & 3 & 4 & 5 & 6 & 7 & 8 & 9 & 18 & 11 & 12 \\
\hline & $T$ & $T$ & $T$ & $T$ & $T$ & $T$ & $T$ & $T$ & $T$
\end{tabular} 
SHEET (See instructions)

4. TITLE AND SUBTITLE

DEMAND LIMITING ALGORITHMS FOR ENERGY MANAGEMENT AND CONTROL SYSTEMS

5. AUTHOR(S)

Cheol Park

6. PERFORMING ORGANIZATION (If joint or other than NBS, see instructions)

7. Contracu Grant No.

NATIONAL BUREAU OF STANDARDS

DEPARTMENT OF COMMERCE

8. Type of Report \& Perlod Covered

WASHINGTON, D.C. 20234

9. SPONSORING ORGANIZATION NAME AND COMPLETE ADDRESS (Street, City, Stote, ZIP)

Office of Buildings and Community Systems

U.S. Department of Energy

1000 Independence Avenue, SW

U.S. Navy Civil Engineering Laboratory

Washington, DC 20585

10. SUPPLEMENTARY NOTES

[ Document describes a computer program; SF-185, FIPS Software Summary, is attached.

11. ABSTRACT (A 200-word or less factual summary of most significant information. If document includes a s/gnificant bibliography or literature survey. mention it here)

Demand limiting control is one of popular control strategies for electrical energy management in Energy Management and Control Systems (EMCS) in commercial/office buildings. The purpose of demand limiting is to maintain the peak demand level below a predetermined limit by shedding nonessential loads in a building during the peak demand period. In this present report, description of fixed interval metering and sliding window metering for electrical demands are included. Demand limiting calculation procedures discussed are the ideal rate, the predictive, and the instantaneous rate methods. Demand limiting algorithms, which were developed based on available information, are presented. Computer program listings of demand limiting control algorithms in Fortran 77 and an open-loop computer simulation result are included in the appendices.

12. KEY WORDS (Six to twelve entries; alphabetical order; capitalize only proper names; and separate key words by semicolons) electrical demand; electrical energy management; electric power; energy management and control systems; fixed interval metering; ideal rate method; instantaneous rate method; load control; predictive method; sliding window metering.

13. AVAILABILITY

[X] Unlimited

For Official Distribution. Do Not Release to NTIS

Order From Superintendent of Documents, U.S. Government Printing Office, Washington, D.C. 20402.

14. NO. OF PRINTED PAGES

\section{8}

15. Price

$\$ 11.50$

X] Order From National Technical Information Service (NTIS), Springfield, VA. 2216I 

